\title{
Addressing the Elephant in the Room: A Descriptive Analysis of Weight-Based Harassment on College Campuses
}

Lynnsie Doty

West Virginia University

Follow this and additional works at: https://researchrepository.wvu.edu/etd

\section{Recommended Citation}

Doty, Lynnsie, "Addressing the Elephant in the Room: A Descriptive Analysis of Weight-Based Harassment on College Campuses" (2014). Graduate Theses, Dissertations, and Problem Reports. 135.

https://researchrepository.wvu.edu/etd/135

This Thesis is protected by copyright and/or related rights. It has been brought to you by the The Research Repository @ WVU with permission from the rights-holder(s). You are free to use this Thesis in any way that is permitted by the copyright and related rights legislation that applies to your use. For other uses you must obtain permission from the rights-holder(s) directly, unless additional rights are indicated by a Creative Commons license in the record and/ or on the work itself. This Thesis has been accepted for inclusion in WVU Graduate Theses, Dissertations, and Problem Reports collection by an authorized administrator of The Research Repository @ WVU. For more information, please contact researchrepository@mail.wvu.edu. 
Addressing the Elephant in the Room: A Descriptive Analysis of Weight-Based Harassment on College Campuses

\author{
Lynnsie Doty
}

Thesis submitted to the College of Arts and Sciences

at West Virginia University

in partial fulfillment of the requirements

for the degree of

\author{
Master of Arts \\ in \\ Sociology
}

\author{
Karen Weiss, Ph.D., Chair \\ Lisa Dilks Ph.D. \\ Amy Hirshman, Ph.D. \\ Department of Sociology
}

Morgantown, WV

2014

Keywords: weight, bullying, harassment, college campuses, fat studies Copyright 2014 Lynnsie Doty 


\section{Abstract \\ Addressing the Elephant in the Room: A Descriptive Analysis of Weight-Based Harassment on College Campuses}

\section{Lynnsie Doty}

According to the bullying and harassment literature, over 50 percent of adolescents reported that they were targets of harassment at least once a month. A major gap within this literature is that most of these studies focus predominantly on adolescents and none focuses on older cohorts. To date only five studies have focused on college populations, but none focus on weight specifically as a factor. Although many individuals may disagree, weight-based harassment is comparable to harassment based on race and sexual orientation and affects victims just as negatively. Therefore, it is time to address the elephant in the room and to explore what weight-based harassment looks like on college campuses. The current study conducted the first descriptive study of weight-based harassment by administering a questionnaire to a random sample of 8,000 undergraduate students attending a large, north-central, land grant, University during the fall of 2013. Analysis of descriptive statistics and bivariate analyses show that students of all sizes are targeted for their weight. Results also found that most incidents of weight-based harassment occur within the context of the party-subculture in hotspot locations where alcohol is involved. The current study also found targets either avoided or stopped going to certain locations because of being harassed. The results of the current study fill the gaps and extend knowledge of bullying, harassment, and Fat Studies literature. The current study found that weight-based harassment is a serious problem with serious consequences that not only merits the attention of researchers, but also deserves the recognition as a legitimate form of harassment and prejudice. The findings of the current study will aide researchers of bullying, harassment, and weight bias in future research and could be used by Universities to inform policy change. 


\section{Dedication}

This thesis is dedicated to any and all persons who have ever been made to feel bad about themselves because of their weight and who felt like they had no one to stand up for them. You are not alone nor is there anything wrong with you. Love the body you are in and remember that you are unique and that is beautiful. Remember, you always have a voice even if others try to silence you. This thesis is also dedicated to Dr. Deborah Christel who introduced me to the world of Fat Studies and showed me that I was not alone in my beliefs and convictions of equality. She inspired me, along with the other fat activists and researchers within the Fat Studies realm, to have the courage to stand up against ignorance and the confidence to stand up as a fat activist in a world that tells me I am wrong. To those who think it is still acceptable to make fun of someone because of their weight, one day I hope that you will be able to open your hearts and minds to love and acceptance. 


\section{Acknowledgements}

I would like to begin by acknowledging my thesis committee. First, I would like to acknowledge Dr. Karen Weiss, my committee chair. Dr. Weiss encouraged me to follow my heart and supported my research interests of exploring weight bias when so many told me that weight bias was not important or was not a do-able topic. Dr. Weiss was a tough chair, but she always pushed me to be a better writer and researcher. For her support, I will always be thankful. Second, I would like to acknowledge Dr. Amy Hirshman, a member of my committee. Dr. Hirshman was always available to discuss my research and work through the arguments that I was trying to make in my thesis. Dr. Hirshman also pushed me to be a better writer by making me acknowledge my writing faults specifically my abuse of commas and clauses. Thank you, Dr. Hirshman for all of your help, for showing me how I can improve my writing, and for all of your advice for the future. Third, I would like to acknowledge my final committee member, Dr. Lisa Dilks. Dr. Dilks helped me with my thesis in so many ways. Dr. Dilks put up with all of my complaining, all of my questions about the data, and all of my emails (which there were several). Thank you, Dr. Dilks for putting up with me and for helping me any way you could; I will never be able to thank you enough. I am grateful and appreciate all three of you.

Next, I would like to acknowledge my roommates. First, I would like to thank Angela. Angela, thank you so much for your support and for listening to me talk about my thesis all the time. Thank you, for never letting me give up and encouraging me every step of the way, you have been a great friend to me. Second, I would like to acknowledge Barbara and my fur-niece, Fluffers. Barbara, you kept me sane throughout this entire process and I do not know what I would have done without you. By the end of this process, you were an honorary committee member and I cannot find the words to thank you for all of your support, your encouragement, and everything you have done for me. You have been an amazing friend and amazing support system. You have become one of my best friends and I am so appreciative and grateful for you and Angela. Third, I would like to thank Fluffers. Fluffs, you have been the best little therapy cat. You always knew when I was stressing out about my thesis and you always cuddled with me to make me feel better. Thanks for being the best fur niece an Aunt could ask for.

Finally, I would like to acknowledge my family, my boyfriend's family, and my boyfriend, Karol. I would be nothing without my family and Karol; they are everything to me. I would first like to thank my entire family for all of their unconditional love and support. There are not enough words to express my gratitude and love for all of you. I am a very lucky and fortunate young woman to have been blessed with such an amazing family and support system. I am also a very lucky girl because I have the support of two families, my own and the Kelleys. I would like to thank Paul, Donelen, and Rozi for all of their love, support, and prayers. They have cared for me like my own family and I am so grateful and appreciative of all they have done for me. I would now like to thank my best friend and my rock. Karol, you are my everything and I would be lost without you. You have always been my cheerleader and you have helped me in so many ways that I will never be able to thank you enough. I love you so incredibly much, I am so thankful for you, and I cannot wait to see what our future holds. Finally, I would like to thank God. I may not understand your plan for me and maybe I am not supposed to, but I am thankful for the life you have given me and the opportunities you have set before me. 
Table of Contents

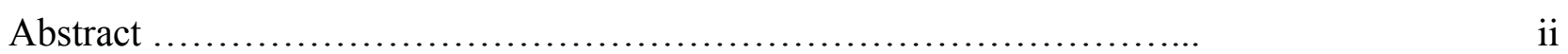

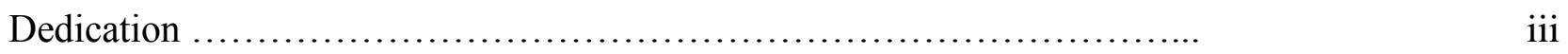

Acknowledgements ........................................... iv

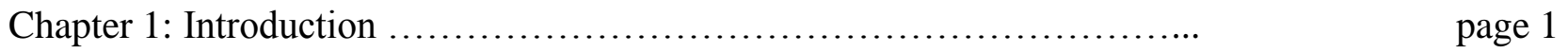

Chapter 2: Bullying and Harassment ..................................... page 7

Chapter 3: Weight-Based Harassment........................................................ page 20

Chapter 4: Research Objectives ................................... page 31

Chapter 5: Methods ........................................... page 32

Chapter 6: Findings ............................................... page 50

Chapter 7: Discussion......................................... p page 58

Chapter 8: Conclusion .............................................. p page 64

References ...................................................... p page 70

Appendix A ........................................................ Page 85

Appendix B ..................................................... Page 86

Appendix C ................................................. p page 87

Appendix D .................................................. page 88

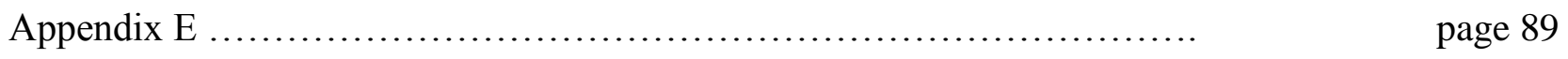

Appendix F ................................................... p page 90

Appendix $G$..................................................... p page 91 


\section{Chapter 1: Introduction}

On November 07, 2011, 10-year old Illinois native, Ashlynn Conner took her own life after being bullied because of her weight (Matthews 2011). Although Illinois had recently passed an anti-bullying law in 2001, it was not enough to save Ashlynn's life (Matthews 2011). In an interview Connor's mother stated, 'I don't know what it's going to take to stop it, but no child should ever have to feel like they have to kill themselves to stop that kind of pain" (Matthews 2011). Regrettably, Ashlynn is just one of many adolescents who end their lives due to constant torment from peers. Among young people suicide is the third leading cause of death. Victims of bullying are 2-9 times more likely to commit suicide than those who are not bullied (Ark of Hope for Children 2013). Ashlynn's story illustrates how these situations have the potential to become a matter of life and death. More importantly, these senseless deaths show that these behaviors are far from just "kids being kids" as others have argued (StopBullying 2012; U.S. Department of Education 2011).

Research estimates that over one million adolescents are affected to some degree by bullying, and 71 percent of students indicate that bullying is a major problem at their schools (Ark of Hope for Children 2013; Nansel et al. 2001). As for weight-based bullying, Fox and Farrow (2009) found that fat students are more likely to be targets of bullying than their "average" weight peers, and that as body weight increases, so does the frequency of bullying. Puhl (2011) also found that 40.8 percent of students reported, "Being over-weight" as the primary reason for being bullied. The National Education Association (1994) suggests, "For fat students the school experience is one of ongoing prejudice, unnoticed discrimination, and almost constant harassment" (as cited by Wann 2009: p. xix). 
The effects of discrimination and harassment have a lingering and significantly negative impact on the physical and psychological health of those targeted. Targets of weight-based bullying report feelings of depression, isolation, anxiety, low self-esteem, and suicidal ideation (Gladstone et al. 2006; Hamburger et al. 2011; Hawker and Boulton 2000). Harassment also affects daily routines by creating hostile environments. A hostile environment exists when individuals fear and avoid certain places or situations because of being harassed (FCC 2009). The bullying and harassment literature discussed above, as with most of this literature, focuses predominantly on adolescents (Espelage and Swearer 2003), but the population of interest for the current study is college students. Only five studies have explored bullying and college campuses and none of these look specifically at weight as a factor (Chapell et al. 2004; 2006; MacDonald and Roberts-Pittman 2010, 2012; Reason and Rankin 2006).

Due to these gaps, the current study builds upon the existing literature in two important ways. Firstly, this study extends the bullying and harassment literature by focusing on collegiate level populations. It is important to focus on college students because if there are other vulnerable populations they should be explored to provide more information into the dynamics and patterns of bullying. Research also suggests that college students have more resources available to them to target others but to cope as well, so it could become a matter of safety for not only students but campus as well. Secondly, this study extends the bullying, harassment, and Fat Studies literature by focusing on weight as a target. Focusing on weight is important because "Fat discrimination is one of the last publicly accepted discriminatory practices" (NAAFA 2013). Therefore, the research question for this study is what does weight-based harassment look like at the college level? 
In order to answer this question data from Weiss's (2013) College Harassment Survey CHS) was used. The survey was administered to a random sample of undergraduates attending a large, north central, land-grant University. Using the results from the online survey the current study describes incidents of weight-based harassment and examines the effects that harassing comments have on student's well-being. The results of this study will be used to advocate for more research on weight-based harassment on college campuses and the acknowledgement of weight-based harassment as a legitimate form of harassment. As fat students are not protected as a group, the results will also be used to advocate for an open and honest discourse with the Universities into the treatment of fat students. Results from this study will show that weightbased discrimination is a problem for college students and that this behavior merits attention from researchers and University officials.

\section{Structure of Thesis}

This thesis begins by discussing the literature on bullying and harassment amongst youths in Chapter 2 because much of this literature focuses on this population (Espelage and Swearer 2003). Continuing to study this behavior among adolescents is necessary for a better understanding of the issue, but a weakness of this literature is its lack of focus on other potential vulnerable age populations such as college students. Even though the population of interest for the current study is at the collegiate level the current thesis will also discuss the literature on youths in order to establish patterns in the literature that could be applied to young adults. As a major assumption of this literature is that bullying ends in high school it is important to make connections as to how the behavior could bridge the gap between the two age groups.

It is naive to assume that bullying and other harassing behaviors simply stop after high school; especially since the prevalence, risk, and lingering impacts associated with these 
harassing behaviors is largely discussed in the literature (MacDonald and Roberts-Pittman 2010). Although the topic and form of harassment may change with age, individuals simply do not age out of negative comments and actions aimed at others (Chapell et al. 2004; 2006; MacDonald and Roberts-Pittman 2010). Research suggests that the only difference between age and harassment is that older parties have more resources available to them to facilitate or to cope with the bullying or harassment (Chapell et al. 2006). Finally, Chapter 2 will discuss the major findings from the bullying literature to establish the broader patterns and will then the thesis will narrow its focus to literature on being bullied or harassed specifically by weight.

Chapter 3 will switch focus and will discuss the burgeoning field of Fat Studies as well as the bullying and harassment literature on weight targeting for adolescents and adults. Similar to the bullying and harassment literature, there is a gap in research between adolescents and adults with young (collegiate) adults largely overlooked (Espelage and Swearer 2003).

Despite this major oversight in the literature one fact remains true, weight is a factor for being targeted. Though many individuals may refuse to believe that the treatment of fat people is comparable to the treatment of racial minorities, research by Puhl et al. (2008) found that the rates of weight discrimination are as relatively close to as the rates of both racial and age-based discrimination. This finding, though surprising to individuals who have never experienced weight bias, come as no shock to individuals who have been targeted for their weight at some point in their life.

Worse yet are the impacts and consequences that fat persons experience because of discrimination, bias, and stigma. Similar to targets in the bullying and harassment literature, the effects of being targeted because of weight is crippling psychologically and physically (Schafer and Ferraro 2011). The effects for being targeted for weight may be more powerful for fat 
persons, considering they are not part of a protected group and have very few allies (Puhl et al. 2008). This is why the current study will focus on weight as a factor for being targeted on college campuses and surrounding areas.

Universities are meant to provide safe locations where persons of all sizes and differences can come together and share in their pursuance of a higher education. However, it is not known how fat students are targeted or affected by weight bias on the college campus. Chapter 4 will thus provide readers with a discussion of the research objective of the current study, which is to describe weight-based harassment at the college level, by providing descriptive accounts of the incident that had the most impact on students. These accounts will provide descriptives of the target, the aggressor(s), where and when the incident occurred, how the students were targeted, and what affects and consequences, if any, that students experienced because of being targeted for their weight. The current study will also provide descriptives on bystander intervention, whether or not someone intervened to help or to make matters worse.

Chapter 5 will then inform readers of the methods used to collect the descriptives. The current study used a questionnaire, designed by Karen Weiss (2013a), which will be referred to as the College Harassment Survey (CHS). The CHS combines both close-ended and open-ended questions and asked respondents about their experiences with harassment, specifically weight, on the college campus. The CHS was sent to a random sample of 8,000 undergraduate students attending a large, north central, land-grant University. Chapter 6 will then highlight the findings of the current study, which will then be used to not only fills the gaps and extend the knowledge in the bullying, harassment, and Fat Studies literature, but will also advocate for more research and acknowledgement of weight-based harassment on college campuses in the final two chapters. Chapter 7 will connect the findings of the current study with the literature discussed in 
Chapters 2 and 3. Chapter 8 will then finally discuss the importance of the current study's findings as well as the implications of the findings. The results of the current study will fill the gaps and extend knowledge of bullying, harassment, and Fat Studies literature. The current study will show serious of problem with serious consequences that weight-based harassment is. Weight-based harassment on college campuses merits the attention of not only researchers, but also deserves the recognition as a legitimate form of harassment and prejudice. The findings of the current study will aide researchers of bullying, harassment, and weight bias in future research and could be used by Universities to inform policy change 


\section{Chapter 2: Bullying and Harassment among Youth and Young Adults}

\section{Language and Definitions}

A major point of contention in the bullying and harassment literature focuses on the definitions and language to use when discussing this negative behavior. The conversation begins with whether to label the behavior harassment or bullying and then how it is measured. It is important to note that this academic difference in opinion is widespread and researchers rarely agree on one definition (Hamburger et al. 2011). The reason for this disagreement on language is that researchers and the public seem to be more comfortable in using bullying when adolescents are discussed. Others view bullying as a juvenile behavior and prefer to use the term harassment instead for adults. Despite the agreeability or lack thereof on definitions, most researchers have adopted or adapted the definition of Daniel Olweus (Hamburger et al. 2011; Olweus 1994).

Olweus is considered a pioneer and the founding father of bullying research; he conducted the first known study of this behavior in adolescents (Juvonen et al. 2001; Olweus 1994). Olweus (1994) stated:

A person is bullied when one or more others expose him or her repeatedly over time to negative actions, excluding cases where two children of similar physical and psychological strength are fighting (Olweus 1994). Olweus added that bullying can be direct (open attacks that are physical or verbal in nature) and indirect (exclusion) (as cited by Hamburger et al. 2011).

Despite the variability among definitions in the literature, most researchers do agree that bullying experiences include verbal and physical harassment (Hamburger et al. 2011). The United States Department of Education Office of Civil Rights stated:

Bullying is a form of harassment, which can include verbal, written, or cyber namecalling, can be physically threatening or humiliating, and does not necessarily have to include an intent to harm, be directed at a specific target, or involve repeated incidents (as cited by Charmaraman et al. 2013: p. 439). 
Because of this agreement the current study similar to Juvonen et al. (2010) will use the terms bullying and harassment interchangeably and as synonyms for victimization. With the previous definitions in mind, the current study will use Weiss' (2013a) definition of harassment. Harassment is being called derogatory names, threatened or intimidated by offensive or sexual comments that make the target uncomfortable (verbal harassment), and being attacked, shoved, hit, or kicked without provocation (physical harassment) (Weiss 2013a).

\section{Prevalence and Patterns of Harassing Behaviors among Youths}

Daniel Olweus (1993) found that in the American school system there are approximately 2.1 million bullies and 2.7 million victims (as cited by Ark of Hope for Children 2013), while Card et al. (2008) found that 70 percent of students report having been affected by bullying in some form. Research on adolescents also has found that "one-third of youth are bullied at least once a month while other studies found that six out of 10 American teens witness bullying at least once a day" (National Crime Prevention Council 2010). These statistics confirm that adolescents are frequently subjected to abuse. In some areas of adolescent research bullying is treated as an epidemic (Cardin 2013). These studies as with most on bullying focus on adolescents and overlook young adults (Espelage and Swearer 2003). Because of this oversight the current study will begin by discussing the major findings of the research on adolescents in order to provide a basis with which to situate what is known about collegiate level harassment.

\section{Targets and Sources of Bullying and Harassment Amongst Adolescents}

Literatures on adolescents and bullying have found that harassment is a gendered experience. Nansel (2001) found that aggressors were more likely to be younger males whereas the Center for Disease Control and Prevention (2011) found that females were more likely to be targeted than males. Nansel (2001) claimed for targets, "no single factor puts a child at risk of 
being bullied or bullying others, but bullying can happen anywhere, and depending on the environment, some groups may be at an increased risk of being bullied" (StopBullying 2012). Most researchers do agree that bullying occurs because of some perceived difference between students (e.g. weight, race, sexual orientation, etc.). Researchers have begun to explore these differences for adolescents especially for weight (Puhl et al. 2011). These perceived differences have yet to be explored for young adults; as evidenced by MacDonald and Roberts-Pittman (2010) who claimed, "If it [the difference] is by ethnicity or sexual orientation, we do not know. We don't have enough data" (as cited by Indiana State University 2011; National Crime Prevention Council 2012).

In terms of gender, only recently have females as offenders been included in bullying research for youths and young adults (Björkqvist 1994). A common theme between bullying and harassing behaviors is aggression and by all accounts in past adolescent literature women either were seen as not capable of such behavior or female-based bullying occurred so seldom that it was not worth mentioning (Björkqvist 1994; Buss 1961; Olweus 1978). Aggression is formally defined as, "any behavior intended to cause harm" (Bordens and Horowitz 2001: p.366). It is narrow-minded to assume that females are not capable of aggression in adolescents or as young adults. Björkqvist (1994) agrees but stated:

Being physically weaker, they simply have to develop other means than physical ones in order to reach successful results. Accordingly, one should not expect women to develop and use exactly the same strategies for attaining their goals, as men do. If strategies for aggression and conflict resolution are learned, not innate, then women are likely to learn different methods than men (P. 178).

While Björkqvist (1994) made his own assumptions, he made an interesting point. Certainly not all women are physically weaker and women are fully capable of physical aggression, but taking into consideration conventional gender roles, it makes sense that women 
would learn to exhibit aggression differently than men as a whole. Women have been found to favor verbal bullying and other forms of indirect aggression (i.e. the social and relational bullying act of spreading rumors) whereas males are more likely to use physical bullying (Björkqvist 1994; StopBullying 2012). This finding is interesting because research has found that in schools 45 percent of all bullying comes in the form of verbal comments (Juvonen et al. 2001). Instead of focusing solely on gender Björkqvist (1994) believed that emphasis and attention must be paid to the particular conflict (i.e. is the behavior between groups or are they instances of interpersonal conflict). Gender is “of critical importance,” Björkqvist (1994) claimed, and when studying the situation "male-male, female-female, and male-female encounters should be clearly distinguished from each other" (P. 178).

Björkqvist (1994) then went on to state, "With respect to interpersonal aggression, same sex encounters are, for instance, much more frequent than between-sex encounters, but if we limit aggression to physical strategies only, then it is certainly true that males are more aggressive than females, at least in Western societies" (P. 178). While the gender differences in bullying and aggression make the topic much more complex research also suggests that the relationship between those involved in bullying situations is also highly complex (StopBullying 2012). No longer are bullying situations dyadic (StopBullying 2012). This means they are no longer restricted to only one bully and one victim.

Students may be involved as the bully, target, bystander, or a bully-victim (an individual who is a target of bullying and responds by bullying another). In fact, the Stop Bullying Campaign (2012) confirms that adolescents often fulfill more than one role during the harassing behavior. While the roles of the bully, victim, and bully-victim are rather straightforward the 
bullying literature narrows and divides the definition of a bystander into separate categories by focusing on the specific behavioral role they perform (StopBullying 2012).

\section{Bystander Roles and Responses}

Researchers on adolescent bullying and aggression have found that most incidents of bullying happen on the playground and are significant in the fact that most of the incidents are witnessed by large audiences of a students' peers (Fekkes, Pijpers, and Verloove-Vanhorick 2005; Salmivalli, Voeten, and Poskiparta 2011). Similar to the bullying research, most of the literature discussed is on adolescents. Because peer bullying and harassment have been found to be a "group phenomenon" many studies have been conducted on the different participant roles that youth who witness take on during an incident (Espelage, Holt, and Henkel 2003; Frey et al. 2009; Hawkins, Pepler, and Craig, 2001; Salmivalli et al. 1996; Salmivalli and Voeten 2004; Salmivalli, Voeten, and Poskiparta 2011). Bystanders are separated into individuals who assist, who reinforce, outsiders, and individuals who defend (Salmivalli, Voeten, and Poskiparta 2011; StopBullying 2012).

Individuals who assist do not initiate or lead the bullying, but will join the bully and occasionally chime in; mostly their role is as an assistant (Salmivalli, Voeten, and Poskiparta 2011; StopBullying 2012). Those who reinforce, unlike those who assist, take no active part in bullying. These individuals observe the bullying and will cheer, laugh, etc., which may encourage the situation to continue (Salmivalli, Voeten, and Poskiparta 2011; StopBullying 2012).

Outsiders are very different from the previous two categories; these individuals neither assist nor reinforce and choose to stay out of the conflict altogether (Salmivalli et al. 1996; Salmivalli, Voeten, and Poskiparta 2011; StopBullying 2012). Outsiders may watch the behavior 
but remain neutral; they show no allegiance to either party involved. Outsiders may also be referred to as passive bystanders in the literature (Pöyhönen, Juvonen, and Salmivalli 2012; Salmivalli, Voeten, and Poskiparta 2011; StopBullying 2012). Research has found that these outsiders empathize with the victim, but do not know how to stop the bullying situation (StopBullying 2012).

Finally, those who defend are the children who come to the victim's defense and intervene to stop the bullying (StopBullying 2012). While extensive studies have been done to learn more about these bystander roles little research has been done to actually test whether or not these roles of participation have any effect on the frequency of bullying and harassing behaviors (Salmivalli, Voeten, and Poskiparta 2011). What research there is on the influence of bystanders' only focuses on the effects of those who defend the target; none focus on the effects of the roles that support the aggressors except one (DeRosier, Cillessen, Coie, and Dodge 1994; as cited by Salmivalli, Voeten, and Poskiparta 2011).

Salmivalli, Voeten, and Poskiparta (2011) empirically found that bystanders have a profound influence on the frequency of bullying. These researchers found a strong association between the bullying of others and the role of those who reinforce the bullying (positively associated), and found as previous literature had, a negative association between defending the target and the frequency of bullying (Salmivalli, Voeten, and Poskiparta 2011). The previous finding suggests that as more students reinforce the bully and bullying, the frequency of bullying increases. When more individuals defend the target, the frequency of bullying decreases. Salmivalli, Voeten, and Poskiparta (2011) stated:

If bullies indeed seek social power, as has been suggested (e.g., Juvonen and Galvan 2008; Salmivalli and Peets 2009; Sijtsema, Veenstra, Linddenberg, and Salmivalli 2009), they might view reinforcing as an indication of this sought-after high status in the peer group. By 
reinforcing the aggressive acts, the bystanders communicate to the bullies that (a) their behavior is acceptable, even admired, and (b) they do not have to fear retaliation from peers (P. 674).

Defenders of the target may serve more than the obvious function. Defenders may be able to assuage the effects of being targeted. The experiences of those who have supporters are arguably much different from those targets that have no one on their side (Salmivalli, Voeten, and Poskiparta 2011).

While defending certainly is an effective way of curtailing incidents of harassment, evidence suggests that bystanders rarely intervene despite the fact that many youth report that they disapprove of bullying (Boulton, Trueman, and Flemington 2002; Hawkins, Pepler, and Craig 2001; O’Connell, Pepler, and Craig 1999; Pöyhönen, Juvonen, and Salmivalli 2012; Rigby and Johnson 2006; Rigby and Slee 1991; Salmivalli and Voeten 2004; Whitney, Nabuzoka, and Smith 1992). Pöyhönen, Juvonen, and Salmivalli (2012) found that whether a witness intervenes depends on their level of self-efficacy. Self-efficacy, coined by Bandura (1994), is defined as an individuals' belief in their "abilities to succeed in a particular situation" (as cited by Cherry 2014). The higher a witnesses' self-efficacy and the more important that other students' wellbeing are to the witness, the more likely they are to intervene to help the target (Pöyhönen, Juvonen, and Salmivalli 2012). Pöyhönen, Juvonen, and Salmivalli (2012) also found that for students who remained passive their reasoning for doing so is mostly ambivalent.

Students who remain passive believe that intervening to help the target would be the right thing to do, but do not believe intervening would help to decrease the harassment (Pöyhönen, Juvonen, and Salmivalli 2012). If the witness did not care about the targets' well-being or about the bullying decreasing they were more likely to reinforce the bullying (Pöyhönen, Juvonen, and Salmivalli 2012). The roles that witnesses play is important to discuss because their involvement 
in harassing behaviors arguably can add to the distress of the target, seriousness of the situation, and how targets are affected overall by being harassed.

All patterns and findings from adolescents could be applied to young adults. In order to apply patterns from adolescents to young adults, adequate data needs to exist that bridges the gap, but as established there are few. Researchers need a better understanding of the specific reasons that adolescents and young adults are being targeted as well as what harms or consequences, if any, are adolescents and young adults experiencing because of being harassed. While important to establish the issue of harassment and all that it involves, it is also important to address the harms associated with being targeted. These harms merit serious attention from researchers.

\section{Impacts of Bullying and Harassment}

Bullying experiences significantly affect and alter the lives of those who are victimized for both adolescents and young adults. For example, young adult victims report that harassing behaviors affect every aspect of their life in not only an educational setting, but also socially, physically, and psychologically (Weinstock and Krehbiel 2009). Victims of all ages report feelings of depression, low self-esteem, isolation, educational disengagement, social disengagement, multiple health issues, increased levels of stress and blood pressure, anxiety disorders, suicidal ideation, as well as risky, criminal behavior (e.g. vandalism, drug use) (Bond et al. 2001; Eisenberg et al. 2003; Gladstone et al. 2006; Hamburger et al. 2011).

This body of research has also confirmed that for adolescents, these negative impacts stay with them from childhood well into adulthood and "produce long-term negative outcomes" (CDC 2011; StopBullying 2012). Kochenderfer and Ladd (2001) suggest:

Frequent harassment may lead children to develop a sense of mistrust toward their peer group at large and thus become so preoccupied with feelings of social alienation and concerns for their safety that they have difficulty attending to the demands of schools and eventually 
develop negative school attitudes" (Hoover and Hazler, 1991; Kochenderfer and Ladd, 1996; Slee 1994; as cited by Kochenderfer and Ladd 1994: p. 27).

Aside from the physical and psychological effects of harassment, the inability to concentrate and peacefully attend class poses a major problem for not only adolescents but also for college students; the impacts are applicable to both cohorts. Research found that because of harassment adolescent students try to avoid the situation where it occurs (Boulton and Underwood 1992; as cited Kochenderfer and Ladd 2001).

While a concern for adolescents, this finding is especially troubling for college students. College students may be able to seek counseling for issues relating to harassment, but they cannot avoid or miss class because their scholastic endeavors would surely suffer. Avoiding or missing class because of harassment creates a hostile environment. Hostile environments occur when certain locations become so hostile that victims will avoid or stop going to that particular locations or similar locations. Harassment becomes a psychological thriller, where the actual incident has already occurred, but the anticipation and fear of the behavior to happen again becomes a preoccupation in the minds of those who had been targeted. Boivin et al. (2001) stated, "Emotionally, each day of school brings the anticipation of being hurt, humiliated, or terrorized, with all its accompanying tension, anxiety, and fear" (P. 266). Bullying and harassment are more than just nuisance behaviors. The harms associated with these unwanted behaviors are not age specific; these effects and consequences do not have an age restriction to them, all are vulnerable. These aggressive acts have the ability to dominate and dictate every aspect of an individual's life by creating hostile environments. 


\section{Hostile Environments}

The impacts mentioned above are commonly reported on surveys. However, less attention is paid to how these behaviors have the ability to affect the daily routines of targets. This component of harm caused by bullying is what sexual harassment researchers refer to as hostile environments. According to the U.S. Equal Employment Opportunity Commission (2008):““...when conduct explicitly or implicitly affects an individual's employment, unreasonably interferes with an individual's work performance, or creates an intimidating, hostile, or offensive work environment," this constitutes a hostile environment (as cited by Bursik and Gefter 2011: p. 332). Even though this definition is used in terms of employment, the same principles can be applied to academia. Academia provides a professional work environment where students gather regularly to work towards a higher education.

In thinking about hostile environments and how it affects education, the Center for Disease Control (2012) found that on one or more days, 5.9 percent of students missed school because of being harassed and bullied. Ark of Hope for Children (2013) further found that 15 percent of school absenteeism is also due to bullying and harassing behaviors. They also report that 1 in 10 children who drop out of school do so because of bullying (Ark of Hope for Children 2013). Bayliss (1995) further found that girls, because of harassment and bullying, do not want to go to school and once there will only choose courses that will help them avoid bullying or harassing (as cited by Shute et al. 2008).

It is not enough for adolescents and young adults to suffer physically and psychologically, but these hostile environments created by bullying and harassment will define these individuals entire world, where they go, what they do, and with whom they interact. The above findings are 
unsettling because where education is concerned, no student young or old should fear having to go to school. Schools are meant to be safe environments. As Dan Olweus (1993) stated:

I have for a long time argued that it is a fundamental democratic or human right for a child to feel safe in school and to be spared the oppression and repeated, intentional humiliation implied in peer victimization or bullying. No student should be afraid of going to school for fear of being harassed or degraded, and no parent should need to worry about such things happening to his or her child (Olweus 2001: p. 12).

This fear of going to school for fear of being harassed, as the current study will show, is very real for young adults. College campuses, students, harassment, and affects of harassment were barely addressed by researchers, which is why the current study aims to highlight this oversight by focusing on older populations (Nansel et al. 2001). One possible reason that researchers do not focus on this cohort may be that many individuals assume that bullying ends in high school (Cardin 2013). As argued in Chapter 2, research has confirmed that bullying does continue and that colleges provide unique spaces different from middle or high schools with greater resources for individuals to harass others or to cope with being harassed (Chapell et al. 2004; 2006). Since only a handful of studies have focused on college populations the findings of these studies will be discussed in order to situate the significance and importance of the current study.

\section{Harassment and Bullying on College Campuses}

Very little is known about students' experiences with harassment on college campuses. In fact, only five studies have addressed the issue of harassing behaviors on the college campus (Chapell et al. 2004; 2006; MacDonald and Roberts-Pittman 2010; 2012; Reason and Rankin 2006). In one of these studies, Chapell et al. (2004) examined the frequency of bullying between students and professors. These researchers found that out of a sample of 1,025 undergraduates, 24.7 percent of students witnessed a student bullying another student occasionally while 2.8 
percent of respondents said they witnessed this same behavior very frequently. Chapell et al. (2004) also found that 5 percent of students reported having been bullied by another student occasionally, and 1.1 percent of students said that they were bullied very frequently. As for professor involvement with bullying, Chapell et al. (2004) found that 12.8 percent of students witnessed a teacher bullying a student occasionally and 4.2 percent of students reported having been targeted by a professor occasionally. Chapell et al. (2004) even captured that 3.2 percent of students admitted to bullying other students occasionally. Similar to literature on youths, Chapell et al. (2004) found that harassment was a gendered experience where males were more likely to be the aggressors than females.

In their second study, Chapell et al. (2006) found that out of the 25 students who had been bullied in college, 72 percent had also been bullied in both primary and secondary education. Out of 26 students who identified as being bullies in college, 53.8 percent indicated that they were also bullies in both primary and secondary education. Chapell et al. (2006) further found that out of 12 students who identified as being a bully and a victim in college, 41.6 percent had been both a bully and a victim in primary and secondary education.

MacDonald and Roberts-Pittman (2010; 2012), in their two studies of bullying and harassing behaviors on college campuses, found that 15 percent of students reported being bullied and 21.9 percent of students in their sample reported being cyber-bullied. They further found that 42 percent of students reported having witnessed a student being bullied by another student and 8.4 percent had admitted to bullying other students (MacDonald and Roberts-Pittman 2012). In their 2010 study, MacDonald and Roberts-Pittman found no gender differences in bullying, but in their 2012 study they found that males were more likely to be the aggressors and 
females were more likely to be the targets, which is consistent with previous literature and the fifth study on college students and bullying (Reason and Rankin 2006).

Reason and Rankin (2006) examined the differences in harassment experiences for men and women. Their findings were consistent with previous literature on adolescents. Reason and Rankin (2006) found that both men and women reported having been harassed, but women were harassed at statistically significant higher rates. Based on the findings of Reason and Rankin (2006), among the others cited in the literature on adolescents and bullying, the current study expects to find similar gendered results. These studies on young adults confirm that harassment is still a problem for older populations despite research that claims that as teenagers grow older the less likely they are to bully (Nansel et al. 2001). While the studies discussed above provided frequencies of harassment and identified the aggressor, none of these studies provides in depth accounts of the incident nor do they focus on the reasons for which individuals were targeted. In order to fill the gap of the reasons for targeting the current study will focus on weight as a factor. Evidence suggests that for fat students, schools become a place of torment and torture and the more an individual weighs, the likelihood of their being harassed increases (The National Education Association 1994; Puhl et al. 2008; Wann 2009). 


\section{Chapter 3: Addressing Weight-based Harassment}

\section{Current Study's approach to Fat Studies}

This chapter takes a Fat Studies approach to address the issue of weight-based verbal harassment on college campuses. Fat Studies is a radically new theoretical and analytical approach to fat activism that promotes human diversity and challenges prejudice and discrimination (Wann 2009). Specifically, "Fat Studies is an interdisciplinary field of scholarship marked by an aggressive, consistent, rigorous critique of the negative assumptions, stereotypes, and stigma placed on fat and the fat body" (Solovay and Rothblum 2009: p.2). Many have probably never heard of Fat Studies but fat acceptance movements such as the National Association to Advance Fat Acceptance have been around since 1969 (NAAFA).

Prejudice and discrimination of fat people are not a new phenomenon and fat persons are discriminated in nearly every facet of their lives (NAAFA 2013). Studies have found that weight-based discrimination exists in medical care (Price et al. 1987; Schwartz et al. 2003), education (Crosnoe 2007; Neumark-Sztainer and Story 1999), employment (Haskins and Ransford 1999; Roehling 1999), public policy (Barry et al. 2009), accessibility or spatial accommodations (NAAFA 2013), and in social settings (Chen and Brown 2012; Crandall 1995; Davison and Birch, 2004). Research has even found that in the past decade, the overall prevalence of weight-based discrimination has increased by 66 percent and is now comparable to race-based prejudice (Danielsdottir et al. 2010; McHugh and Kasardo 2012).

Puhl et al. (2008) defined "weight stigma or bias as negative weight-related attitudes toward an "overweight" or "obese" individual. These attitudes are often manifested by negative stereotypes, social rejection and prejudice. Weight stigma includes verbal teasing, physical aggression, and relational victimization" (as cited by Obesity Action Coalition 2014). Watts and 
Cranney (2009) defined anti-fat prejudice as a distinct form of prejudice in which people make judgments about others based on weight (as cited by McHugh and Kasardo 2012). Danielsdottir et al. (2010) further defined anti-fat prejudice as "a negative attitude toward (dislike of), belief about (stereotype), or behavior against (discrimination) people perceived as being fat" (P. 618; as cited by McHugh and Kasardo 2012). Previous research has also found that expressions of antifat attitudes do transition from words into action, such as acts of discrimination (Carr and Friedman 2005). NAAFA (2013) supports this claim by stating, "Our thin-obsessed society firmly believes that fat people are at fault for their size and it is politically correct to stigmatize and ridicule them" (NAAFA 2013). The above definitions, specifically of Puhl et al. (2008) and Danielsdottir et al. (2010), will be used by the current study in order to connect the actions of aggressors with anti-fat ideology.

\section{What and who is fat?}

Fat, also referred to as adipose tissue, is connective tissue that stores fat cells, cushions vital organs, and assists with other physiological processes (NIH 2014). These cells, according to medical professionals and medical agencies, correlate to health (Harvard School of Public Health 2014). According to the medical sphere, the more fat a person has the more at risk they are for decreased mortality and increased morbidity (Harvard School of Public Health 2014). The way to determine who has more fat and who more is at risk is by using the body mass index (B.M.I.); a ratio of an individuals' body height to their weight (Singer-Vine 2009). This ratio then labels the individual as being underweight, average weight, "overweight", or "obese". The American Heart Association (2013) found that 154.7 million Americans age 20 and older are "overweight" or "obese." 
Fat activists and Fat Studies researchers such as Marilynn Wann (2009) argue that not only is the B.M.I. unreliable, but that the labeling of weight into categories do more harm than good. Fat Studies researchers adamantly believe that the "O-words are neither neutral nor benign" (Wann 2009: p. xii). According to Marilyn Wann (2009):

"Over-weight" is inherently anti-fat. It implies an extreme goal: instead of a bell curve distribution of human weights, it calls for a lone, towering, unlikely bar graph with everyone occupying the same (thin) weights. If a word like "over-weight" is acceptable and even preferable, then weight prejudice becomes accepted and preferred. It is not meaningful to call weights "normal" or "abnormal" (P. xiii).

These popular categorizations are faulty at best and deny all other factors that contribute to differences in weight (Wann 2009). Similar to a bell curve, weight and height are naturally occurring characteristics that vary across populations (Flegal 2006; Wann 2009). As an individual's height changes over the course of their life so too will their weight. Just as some people are naturally short or tall some people are naturally fat or thin (Wann 2009). It is important to note that these variations over time are largely influenced by both biological and environmental factors (Hainer et al. 2001; Wann 2009). In fact, "heights and weights also vary between populations and time periods, due in large part to levels of economic development, access to food, advances in medicine and immunization, and other large scale factors" (Kolata 2006; as quoted by Wann 2009: p. x).

Fat Studies researchers further argue that using the O-words to define health, as the CDC and the NIH does, medicalizes diversity. Medicalizing diversity, especially fat, means taking a naturally occurring difference (diversity) and imposing the connotation that something medically is wrong with that difference (Wann 2009). While many individuals believe that the medicalization of fat may be a good thing, it actually "inspires a misplaced search for a 'cure' for naturally occurring differences. Far from generating sympathy for fat people, medicalization of 
weight fuels anti-fat prejudice and discrimination in all areas of society"” (Wann 2009: p. xiii). Therefore this study, similar to the movement in the Fat Studies literature, will refer to higher weight individuals as fat and will place the terms "overweight" and "obese" in scare quotes to "indicate their compromised status" when discussing research that uses these terms (Wann 2009: p. xii). The world was not always this way, overly critical of weight. There was a time when being fat was considered desirable and trendy and not scrutinized or stigmatized.

\section{Social Construction of Fat as Undesirable}

Between the 1880s and the 1920s, Woods Hutchinson, a medical professor, wrote, "adipose, while often pictured as a veritable Frankenstein, born of and breeding disease, sure to ride its possessor to death sooner or later, is really a most harmless, healthful, innocent tissue" (Hutchinson 1894: p. 395; as quoted by Fraser 2009: p. 11). Hutchinson claimed that not only was fat harmless, but also was beautiful (Fraser 2009). Being fat was "the very picture of American prosperity and vigor" during this period (Fraser 2009: p. 11). Americans of the nineteenth century and previous centuries believed that being fat was a visible sign of wealth (Fraser 2009). If one was fat those individuals had more than enough money to buy large quantities of food. Americans during this time also believed that those who were fat were healthier because their fat made them better able to ward off disease (Fraser 2009).

In the 1920s, fat was declared bad and thin was declared socially acceptable (Fraser 2009). Leading this charge were members of the medical profession, personal trainers, and the fashion industry (Fraser 2009). To answer the pressing question of why, sociologically, the underlying mechanism must be examined. Similar to the Prohibition era, fat like alcohol was never really the problem; "Europeans had long considered slenderness a sign of class distinction and finer sensibilities" (Fraser 2009: p. 12). During the nineteenth century, a time of 
Industrialization, the economy was rapidly changing. With a combination of increased immigrants and prosperity, food was made available to all but the absolute poorest (Fraser 2009). This public unrest and the need for Americans to be able to separate themselves physically from immigrants and the lower classes set in motion the creation and affirmation of fatness as a social problem; the fat is bad mentality of the now (Fraser 2009).

By the end of the $19^{\text {th }}$ century, science was beginning to back the new demand for thinness despite encouraging people to gain weight a few years before (Fraser 2009). Fraser (2009) said: "in short, a cultural obsession with weight became firmly established in the United States when several disparate factors that favored a desire for thinness-economic status symbols, morality, medicine, modernity, changing women's roles, and consumerism- all collided at once" (P. 13). The social construction of thin as desirable, maintained by popular scientific research and media misinforms individuals on true health as well as warps their attitudes about their bodies and the bodies of others. The prejudice and stigma of this fat is bad discourse causes individuals to be in constant fear of fat. This fear also causes some individuals to go to extreme lengths as not to become fat. This fear also reinforces narrow views of body and health and are alienate and ostracize those individuals who do not meet those standards (Wann 2009). These narrow views of health and beauty are quite harmful to the entire population (Wann 2009).

\section{Weight-Based Discrimination}

In a nation where a former U.S. surgeon general C. Everett Koop referred to "obesity" as a form of homegrown terrorism and declared a war on fat and fat people discrimination is a primary concern (Carmona 2003; Levy-Navarro 2009). However,

[If] we started to treat Americans as Americans, not as fat ones, thin ones, short ones, tall ones, brown ones, green ones, yellow ones, or white ones, but as Americans. If we did that, we would not need to worry about discrimination (Humphrey, 110 Cong. Rec. 5866 1964; as quoted by Solovay and Rothblum 2009: p. 4) 
Unfortunately, that is not the mentality of the contemporary population and Fat Americans face adversity, stigma, prejudice, and discrimination everywhere they turn. Being fat is highly stigmatized in American culture. Fat persons are vulnerable to bias, prejudice, and discrimination in a multitude of settings, from employment, health care, education, to even their personal relationships (Puhl et al. 2008). Royce (2009) stated, "In a society with a general penchant for punishing difference, and an excessively high regard for bodily appearances as cultural markers, it makes perfect sense that fat bodies will be abused in a variety of ways" (P. 153).

The most common forms of stigma stem from physical obstacles or barriers or the assumptions that over-weight and obese persons are lazy, stupid, un-motivated, lacking selfcontrol, ugly, and gluttonous (Puhl and Brownell 2001; Puhl and Brownell 2006). In medical care, research has found that health professionals, specifically those who specialize in "obesity," exhibit anti-fat bias and attitudes both implicitly and explicitly (Price et al. 1987; Schwartz et al. 2003). Research suggests that healthcare professionals are the primary source of weight- based discrimination and either misdiagnose fat persons or stigmatize them by having discussions about the dangers of the patients weight regardless of the reason for the patients visit (Schwartz et al. 2003; Teachman and Brownell 2001; Wann 2009). Discrimination goes beyond health care providers to the instruments, machines, and attire that are used to assess health (Wann 2009).

As for employment, while taking into account educational attainment and intelligence, women who weighed 25 pounds over the group norm earned about $\$ 14,000$ less than those at or below the norm; while average weight men earned $\$ 9,000$ less than their "obese" counterparts (Haskins et al.1999; Roehling 1999). Weight-based discrimination is a gendered experience. Fat women are held to different standards than fat men are. Weight-based discrimination is even 
existent in public policy. A relationship has been found between those who hold anti-fat attitudes and support for anti-fat legislation (Barry et al. 2009). Among other sources of weight-based discrimination, socially it has been found that parents and even peers exhibit anti-fat attitudes towards their children and friends (Chen and Brown 2012; Crandall 1995; Davisson and Birch 2004).

In academia, studies have shown that girls who were "obese" were less likely to enroll in college after high school than their non-obese counterparts were (Crosnoe 2007). Weight based discrimination in educational settings extends to fat persons being ridiculed by not only their peers, but also their teachers as well (Neumark-Sztainer et al. 1999; Crosnoe 2007). Fat students are also "deprived of places on honor rolls, sports teams, and cheerleading squads and are denied letters of recommendation" (National Education Association 1994: p. 1; as quoted by Wann 2009: p. xix). Research has also found that fat students experience "ostracism, discouragement, and sometimes violence;" these findings are important for this particular study, which aims to capture these experiences for fat students (National Education Association 1994: p.1; as quoted by Wann 2009: p. xix). As evidenced by the dates of research published about weight-based harassment not much attention has been to this population until recently.

\section{Targets and Sources of Weight-Based Discrimination}

While it is important to note that males are equally as vulnerable as females, research has found that women are more likely to experience fat bias; similar to the findings in the overall bullying literature (CDC 2011; Puhl et al. 2008; Royce 2009; Underwood and Rosen 2014). Women, minorities, and individuals with lower socio-economic status are more likely to be fat (Wang and Beydoun 2007). Women also experience rates of discrimination more frequently than racial discrimination (Puhl et al. 2001; 2008). As for socio-economic status (SES), a study found 
that "SES is inversely related to adiposity in developed nations, meaning that people at the bottom of the ladder for income, education, wealth, and status are much more likely to be fat than the upper classes; this relationship is also much stronger for adult women than for men" (Ersnberger 2009: p. 32).

Research has further found that "woman appear to be at risk for discrimination at far lower weights, relative to their body size, than men" (Puhl et al. 2008; as cited by Tara Parker Pope 2008). This means that women begin to experience significant weight bias when they have gained, or weigh, at least 13 pounds more than their "normal" weight range" (Puhl et al. 2008; as cited by Tara Parker Pope 2008). For men, weight bias does not become noticeable until they have gained or weigh at least 68 pounds over their "normal weight range" (Puhl et al. 2008; as cited by Tara Parker Pope 2008). Royce suggested (2009), "it often does not matter if a woman is really fat; if she lives in a fat-fearing culture... she is likely to be told she is fat, scolded and punished for being fat" (P. 153). Weight, like the bullying and harassment literature, is a gendered issue where women are subjected to inequality more so than men are.

Upwards of 65 million people are considered fat and are potential targets of weight-based discrimination and harassment, but a gap in this literature is the identity of aggressors or bullies (NAAFA 2013). Similar to the bullying and harassment literature, research on fat-based bullying focuses on adolescents in primary and secondary research (Puhl et al. 2011). The patterns for adolescents in education could be congruent with the possible patterns found among college students. Research has found that fat adolescents experience weight-based harassment from multiple sources (Puhl et al. 2011). A study of youths attending a weight loss camp found that 90 percent of youths reported that their tormenters were peers (Puhl et al. 2010). These researchers also found that 42 percent were bullied by a coach or a physical education teacher, 37 percent 
were bullied by a parent, and 27 percent were bullied by a teacher (Puhl et al. 2010).

Unfortunately, no study explores the relationship between targets and aggressors for weight, because no studies focus on weight and college students aside from the current study.

While weight stigma exists in every population research has found that it is also common among obese persons themselves (Schwartz et al. 2006). Fat Studies research suggests that not all "obese" persons view persons like themselves favorably (Schwartz et al. 2006; Wang et al. 2004). Supported by earlier works of Irving Goffman (1963), this research illustrates that fat persons are not only targeted by western society, but because of the discrimination they have experienced they absorb their abuse into negative opinions about themselves and others like them (as cited by Burgard, Dykewoman, Rothblum, and Thomas 2009). Weinstock and Krehbiel (2009) stated, "as long as weight-based oppression remains acceptable, and acceptable body sizes remain narrowly defined, those youth who do not fit the norms will continue to be unfairly and repeatedly targeted" (P. 124).

\section{Impacts of Weight-Based Discrimination}

Research has illustrated that weight prejudice and discrimination permeate nearly every aspect or experience of a fat person's life and that "weight-based discrimination is a cradle-tograve-phenomenon" (Wann 2009: p. xix; Weinstock and Krehbiel 2009). While it is important to discuss how fat persons are discriminated against it is equally as important to discuss how fat persons are affected by the discrimination; especially since research suggests that stigma is much stronger today against fat persons than 40 years ago (Latner and Stunkard 2003). Studies show that the effects of fat stigma on emotional, physical and psychological well-being are crippling (Schafer and Ferraro 2011). Psychologically, studies have established that "obese" persons who internalize stigma are more likely than "average" weight individuals to be depressed, have poor 
body images, lower levels of self-esteem, feelings of hopelessness, and withdrawal (Carr and Friedman 2005; Puhl and Brownell 2006; Schafer and Ferraro 2011).

Fat persons of all ages report feelings of isolation, feelings of hopelessness, and suicidal ideation because of bullying (Bauer et al. 2004; Bond et al. 2001; Carr et al. 2005). Victims also report instances of self-harm; responding to discrimination through risky eating behaviors (e.g. anorexia, binge eating) and academic disengagement (Farrow et al. 2001; Hunte et al. 2011; Neumark-Sztainer et al. 2002). Some fat women report gaining weight and refusing to diet as an act of resistance against the discrimination which can only lead to more torment because as a persons' weight increases, so does the likelihood of their being targeted (Puhl et al. 2007; Puhl et al. 2011). Victims of weight-based discrimination are also more at risk for health related issues (Ernsberger 2009).

Discrimination experienced by health care professionals discourages annual physicals, which mean that the longer these patients wait to see a doctor the more at risk they become for disease or illness (Ernsberger 2009; Poretsky 2013). These patients also run the risk of misdiagnoses due to the prejudice of their medical care providers (Ernsberger 2009; Poretsky 2013). Other studies suggest that the stigma associated with being fat has far worse effects on an individual than actually being fat does (Ernsberger 2009; Poretsky 2013; Sutin and Terracciano 2013). These studies claim that most diseases commonly associated with being fat are actually credited to the stress of stigma than the actual body size (Ernsberger 2009; Poretsky 2013). Schafer and Ferraro (2014) found that the internalization of weight stigma and discrimination caused overall health to decline rapidly especially for physical mobility which greatly relates to the overall health of an individual. 
While many individuals and some researchers believe that fat shaming is more of a motivator than it is an act of discrimination, the remedy of weight loss can take quite the psychological and physiological toll on a fat person (Poretsky 2013). Fat people are prescribed anorexic diets, which fail most of the time and actually can cause health issues on its own (Burgard 2009; Gaesser 2009; Poretsky 2013). The effects of weight-based bullying have the ability to destroy and control lives, are lingering, and remain with the individuals well into adulthood (StopBullying 2012). Wann (2009) eloquently stated, "If we imagine that the conflict is between fat and thin, weight prejudice continues. Instead, the conflict is between all of us against a system that would weigh our value as people... if we cannot feel at home in our own skins, where else are we supposed to go?’(P. xv). Weight bias is still very much socially acceptable and the conflict mentioned above is "rarely challenged and often ignored" (Puhl 2008; as cited by the Obesity Action Coalition 2014). Therefore, the current study will address the elephant in the room by exploring college students' experiences specifically with weightbased harassment on campus and nearby campus locations with descriptive accounts from the perspective of those who had been targeted. 


\section{Chapter 4: Research Objectives}

The objectives of this study are to build upon the existing literatures on bullying, harassment, and Fat Studies by providing descriptive accounts of weight-based harassment on the college campus. Studies of bullying focus predominantly on children and while the data and information collected on this population is vast there is inadequate data on young adults attending college (Espelage and Swearer 2003). Only recently has attention been paid to young adults, aged 18-24 in a college atmosphere, but none of these studies provide a purely descriptive account of what it involves to be harassed on a campus setting and none focus on weight as a factor for being targeted (Chapell et al. 2004; 2006; MacDonald and Roberts-Pittman 2010; 2012; Puhl et al. 2011; Reason and Rankin 2006). The current study will answer the following questions to provide a snapshot look into the experiences of young adults who are harassed based on weight on the college campus. The current study will show what weight-based harassment looks like at the college level.

\section{Primary questions for descriptive analysis}

1. How often does weight-based harassment occur?

2. Where and when does weight-based harassment occur?

3. Who is being targeted?

4. How are targets harassed?

5. What role, if any, do bystanders play in incidents of weight-based harassment?

6. Who are the aggressor(s)?

7. How serious was the incident to the target?

8. What affect did being harassed have on the target?

9. How did the target cope with being harassed? 


\section{Chapter 5: Methods}

A questionnaire designed by Weiss (2013b), which will be referred to as the College Harassment Survey (CHS), was used for the purposes of data collection. The questionnaire, which consisted of both open and close-ended questions, was administered electronically to a random sample of 8,000 undergraduate students attending a large, north central, land-grant University. Weiss' questionnaire survey (2013a) was sent to student email addresses in the form of a link to the web-based questionnaire site SurveyMonkey. The survey itself took between 10 to 15 minutes to complete and the opportunity to complete the survey remained open from November 5 to December 15, 2013 to ensure every student had the chance to complete the survey. Before launching the questionnaire, the survey was piloted in order to correct for any error. After launching the questionnaire, two reminders were sent, once on November 19 and then again on December 12 to the undergraduate email addresses asking for their participation in the study.

The survey was used to collect information about students' experiences with harassment on the college campus. Students were asked how often they experienced both verbal and physical harassment and whether these experiences at college occurred more frequently their experiences in high school. Students were also asked to describe the context of the situation, such as where and when it happened and how many persons were involved. Students also recalled characteristics of the aggressor, as well as how they responded to the incident; whether by reporting to an authority, standing up for themselves, or by doing nothing. Students also described any acts of bystander intervention, and finally, described what impacts and consequences they experienced because of being harassed because of their weight. The 
descriptions discussed above are provided through the close-ended questions. However, respondents were given the opportunity to expand on the incident through open-ended questions. Information collected by the University from winter 2012 through spring 2013 indicated that it has a total student population of 29, 617 students and an undergraduate student population of 22,711 students (Forbes 2013; College Board 2013). Of the student population, 55 percent are male and 45 percent are female (Forbes 2013; College Board 2013). As for enrollment by race and ethnicity, 85.95 percent of students are White, 3.81 percent are African American, 2.86 percent are Hispanic/Latino, and 7.37 percent are Other Races (Forbes 2013; College Board 2013). It is also important to note that in terms of atmosphere, this University is notorious for its rank as a top party school. Weiss (2013b) examined the party school subculture and the crimes (e.g. verbal harassment) associated with partying at this particular University and referred to it as Party University (PU).

Weiss (2013b) stated that most campuses, especially party schools, are safe in terms of serious crime. For party schools, there are a multitude of minor crimes and other nuisance behaviors that all can be explained by the party subculture (Weiss 2013b). Weiss (2013b) asserted that "participation in the party subculture increases students' vulnerability to crime victimization" (Weiss 2013b: p. 73). Drinking not only makes individuals vulnerable to being targets of crimes, but drinking also increases the likelihood of individuals committing or participating in crime themselves (Weiss 2013b). As the University used in the current study was also the focus of Weiss (2013b) it was important to situate the campus atmosphere within the party subculture. Additionally, the current study will use the term college campus as an encompassing term that includes areas surrounding campus where students frequent. 


\section{Participants}

The total sample size for this study was 514 respondents. Four of those cases were 17 year olds who were filtered and dropped from the sample to focus ${ }^{1}$ leaving an overall sample size of 511 respondents. At most 507 undergraduate students answered all questions. Using the 507 respondents, the response rate achieved in this study is 6.3 percent. Out of the 507 respondents who did indicate their age, most were 18-24 year olds (93.8\%). Overall, the majority of respondents were full-time students (97.4\%), upperclassmen (50.5\%), heterosexual (89.2\%), average weight (62.4\%), women (63.3\%), and White (85.7\%) (See Appendix A). These percentages are reflective of the College demographics aside from sex. There are more females in this sample than represented in the University demographics, but previous literature has found that bullying is a gendered experience (Underwood and Rosen 2014).

For individuals who had been targeted by their weight, out of the 511 respondents from the overall sample, 17 undergraduates indicated that they were targeted because of their weight. As to how the sample size went from 511 to 17 for the specific weight section, the survey asked respondents generally, which of the following reasons do you suspect that you were targeted for, check all that apply. However, in another section respondents were asked to pick one specific reason that they suspected that they were targeted for and only 17 chose weight as their specific experience.

\section{Measures}

The CHS asked respondents to describe incidents of both verbal and physical harassment they may have experienced overall and/or in regards to weight on the college campus in openended questions along with bystander intervention, and impacts or consequences the incident may have had on them.

\footnotetext{
${ }^{1}$ The current study only focused on traditional college students aged 18- 24 .
} 
Harassment filter and frequency. The current study first asked respondents to describe their experiences with overall harassment. First, all respondents were asked, "While at the University, have you ever been verbally or physically harassed"? Respondents could have selected from the following:

1. Yes, verbal harassment

2. Yes, physical harassment

3. Yes, both verbal and physical harassment

4. No

If respondents selected options 1,2 , or 3 , they continued on to answer questions about being targeted and overall harassment. If they selected no, they were transferred to the witness section, which will not be used for this particular study. Second, students were asked, "How many times have you been verbally harassed while at the University"? , and third, "How many times have you been physically harassed while at the University"? Both questions had the following answer options:

1. None

2. 1

3. $2-5$

4. $6-10$

5. $11-20$

6. More than 20

Fourth for this section, respondents were asked, "In comparison to high school, such incidents happen". The respondents then had the following choices:

1. More often

2. Less often

3. About the same

This question is important in order to compare patterns of harassment between youth bullying and college students, especially since many assume that bullying ends in high school (Cardin 2013). If respondents select that this type of behavior happens more often, not only does 
that show that the behavior follows students to college, but also that something happens between high school and college for it to increase. The final two questions in this section were included to get an overall sense of what students are being targeted for on campus and how they are being harassed. Sixth, respondents were asked, "For which of the following reasons do you suspect that you were targeted? (Check all that apply)". The available answer options were:

1. Race/ethnicity

2. Religion

3. Sexual Orientation

4. Gender

5. Disability

6. Physical Appearance (dress, piercings, tattoos, etc.)

7. Weight

This question was included to provide a basic understanding of what type of harassment students are experiencing on campus and to gauge whether students' are being targeted for a combination of reasons. Seventh, and the last question in this section, asked respondents, and "In which of the following ways were you harassed? (Check all that apply)". The available answer options were:

1. Verbal comments (insulted, called derogatory names)

2. Threats or intimidating comments

3. Laughed at or made fun of

4. Had items thrown at you

5. Physically attacked (hit, knocked down, shoved)

6. Followed or chased

7. Restricted from/was told not to go into certain places

8. Sent threatening emails or text messages

9. Had embarrassing photos posted online

10. Other (please specify)

Similar to the previous question, this question was included to get a basic understanding of the ways in which students have experienced harassment.

Weight filter. Respondents were then taken to the weight filter, which asked, "Was weight one of the reasons why you suspect that you were targeted for harassment?" Respondents could 
either select yes or no. All respondents who selected yes to weight as a reason for being targeted were asked questions in a weight descriptives section in which all questions focus on one specific experience of weight-based harassment that they have experienced on campus. If they selected no, then they are taken to a section to answer questions about overall harassment in the general harassment descriptive section.

Weight-based descriptives. After students selected yes that they were targeted by weight, they were asked a series of weight-based questions. They were instructed that, "The following questions ask you to describe the details of an incident of WEIGHT BASED harassment while at the University. If you have experienced multiple incidents, please answer the following questions based on the incident that you would consider the most serious or which had the greatest impact on you" (Weiss 2013a). Respondents were first asked in an open-ended question, "Please briefly describe the incident of harassment that had the greatest impact on you". Respondents were then asked, "If you were targeted by WEIGHT or PHYSICAL APPEARANCE, for which of the following characteristics do you suspect that you were targeted". They could have selected from the following:

1. I was not harassed due to weight or physical appearance

2. A physical disability

3. A unique physical appearance

4. A unique style of dress

5. Being fat or overweight

6. Being thin or underweight

7. Being too muscular

8. Other (please specify)

As this study is about weight, all cases were dropped aside from five, being fat or overweight and six, being thin or underweight (coded as $0=$ being fat or overweight, $1=$ being thin or underweight). This question was important in order to narrow the focus to specifically weight as a reason for being targeted. While being fat and "overweight" may be the reason that 
most would assume individuals would be targeted for, and evidence supports that this population is a vulnerable population, it is important to look at weight overall; considering fat and thin are subjective classifications. In addition, the fat studies literature suggests that in a fat hating society and a society that fears fat, persons of every size runs the risk of scrutiny for their size (Royce 2009; Wann 2009).

Spatial and temporal descriptions. Respondents were then asked a series of questions about their most impactful experience with weight-based harassment, including, "Where specifically did this incident occur". Respondents could have selected from the following:

1. Home (house, apartment, dorm room)

2. Classroom/academic hall

3. Other university building (library, student union, gym, etc.)

4. University transportation

5. Fraternity party

6. House party (non-Greek)

7. Student bar/club (inside or right outside)

8. Other University bar/club (inside or right outside)

9. University sporting event (inside or outside)

10. Street

11. Workplace

12. Public building (restaurant, etc.)

13. Other (please specify)

This question was recoded into hotspots. Hotspots are locations such as bars and parties where alcohol is involved. Weiss (2013b) used the term hotspots in her study on the party subculture and crime, which she found are locations where most incidents of crime (harassment) occur. The variable hotspot combined Student bar, Other University bar, Street, House party (non-Greek), and Fraternity party. The rest of the variables were recoded as follows: university locations (combined Classroom/academic hall, Other university building, and University sporting events), public locations (combined University transportation and Public buildings), and then Other 
locations (combined Home, Workplace, and Other). These variables were separated in this way because of the party school reputation of the University.

At this University, several streets are well known as partying zones, which is why they were included in the hot-spots category. Karen Weiss (2013b), in her study on the party school subculture and crime, found and discussed in great detail the connection between alcohol, these hotspots, and instances of crime and verbal harassment. Based on her findings, the current study expects to find that instances of verbal harassment will occur more frequently in hotspots where alcohol consumption is involved.

Respondents were also asked, "Which day of the week did the incident occur". The possible answer options were:

1. Monday

2. Tuesday

3. Wednesday

4. Thursday

5. Friday

6. Saturday

7. Sunday

Students were then asked, "At what time did the incident occur"? The following were answer options:

1. Morning (5am-11:59 am)

2. Afternoon (noon-4:59 pm)

3. Night (5 pm- 11:59 pm)

4. Late Night (midnight- 4:59 am)

Both of these question were recoded to highlight the idea of hot spots and the likelihood of higher frequencies of incidents happening during the weekend (coded $0=$ weekday, or Sunday through Wednesday, and 1 = weekend, or Thursday through Saturday. As well as nighttime when partying is at its highest (coded $0=$ daytime, or morning and afternoon, and $1=$ nighttime, or night and late night). 
Context of the incident. Respondents were also asked a series of questions about the context, such as, "In what manner did the incident occur"? The following were the answer options provided:

1. Electronically (email, Facebook, twitter, text messaging, etc.)

2. Face-to-face

3. While walking by

4. While driving by in a car

5. Other (please specify)

Next, respondents were asked, "Were you alone or part of a group at the time of the incident"? They could have selected from the following:

1. Alone

2. Part of a Group

Then students were asked, "IF PART OF A GROUP, how many people were harassed (i.e. targeted), including yourself?"

1. 1

2. 2

3. $3-5$

4. 6-10

5. More than 10

This question was re-coded by collapsing 6 and up into the variable of more than 10 . These questions are important in order to learn about the dynamics involved in harassment at the college level.

Descriptives of the aggressor(s). This section focused on the aggressor(s), from the perspective of the target. First respondents were asked, "How many person (i.e., aggressors) were responsible for the harassment"?

1. 1

2. 2 
3. $3-5$

4. $6-10$

5. More than 10

This question was re-coded similar to the previous question; 6 and up were collapsed into more than six.

Second, respondents were asked, "What was the gender of the aggressor"? The following were possible answer options:

1. Male

2. Female

3. Both male and female

Although Björkqvist (1994) found that same-sex harassment encounters are much more common, Nansel et al. (2001) found that males were more likely to be the aggressors and the target while Underwood and Rosen (2014) found that females were more likely to be the targets and Reason and Rankin (2006) found that females were more likely to be targets and males aggressors. Responses to this question are important considering the inconsistencies in the literature. The current study expects to find similar to Reason and Rankin (2006) that males are more likely to be the aggressor(s) and that woman are more likely to be the target(s).

Third, respondents were asked, "What was the race of the aggressor(s)"? The possible answer options were:

1. Caucasian/White

2. African American/Black

3. Mixed races (white, black, other)

4. Unsure

Fourth, respondents were asked, "Was/were the aggressors University students"? The answer options provided were:

1. Yes, all

2. Yes, some 
3. No

4. Unsure

The fifth question asked of respondents was, "Did you know the aggressor(s)? With the same, answer options as the question above. If students selected yes, they were then asked, "If YES, which of the following best describes your relationship with the primary aggressor (i.e., the person most responsible for the harassment". The answer options provided were:

1. Friends

2. Intimates/dating partners

3. Roommates/neighbors

4. Coworkers

5. Other University peers

6. Other acquaintances (please specify)

Distinguishing the relationship between the aggressor and the target will provide better information concerning behavioral patterns and it can be argued that the experience of being harassed is very different for individuals who are targeted by someone they know compared to a stranger.

Finally, in this section, respondents are asked, "Did the aggressor(s) appear to be intoxicated"? The answer options provided were:

1. Yes, all

2. Yes, some

3. No

4. Unsure

Targets were also asked if they were intoxicated at the time of the incident $($ coded $0=$ no, $1=$ yes). This question was not included to place blame on the individual for being intoxicated, but to check if Weiss' findings on hotspots, alcohol, and crime could also be found in the current study. As Weiss (2013b) found, alcohol makes students more vulnerable to not only be victimized, but committing or participating in crime. 
Target response and reporting. In this section, respondents are first asked, "How did you respond to the harassment"? The answer options provided were:

1. Yelled, said something back

2. Physically pushed, shoved back

3. Both verbally and physically fought back

4. I did nothing/ignored it

5. Other (please specify)

Second, students were asked, "If you chose to do nothing, which of the following reasons best describes why you did nothing"? The answer options provided for this question were:

1. It was no big deal

2. It happens all the time, what can you do?

3. The aggressors were drunk and probably didn't know what they were doing

4. I did not want to bring any more attention to myself

5. I did not want to get the aggressor(s) in trouble

6. I was too embarrassed

7. I didn't think it would help

8. Other (please specify)

These two questions were important to include, especially the respondents' choice for the second question, because they can provide major insight into how the individual rationalized what happened to them. As Weiss (2013b) found, when looking at a party school, the harms of intoxication crimes are rarely reported because students normalize the behavior through either minimizing the harm or making excuses for the behavior and the aggressor(s).

Respondents were then asked, "Did you report the incident to an authority or tell anyone" (coded as $0=$ no, $1=$ yes)? If they selected yes, they were then asked, "If YES, who did you report the incident to (Check all that apply)".

1. Friend

2. Family member

3. Police

4. Teacher

5. Resident Assistant

6. Employer, supervisor 
7. Therapist/counselor

8. Other (please specify)

If the respondents selected no to the report question, they were then asked "If NO, which of the following reasons best describes why you did not tell anyone about the incident". The answer options provided for this question were:

1. It was no big deal

2. It happens all the time, what can you do?

3. The aggressors were drunk and probably didn't know what they were doing

4. I did not want to make matters worse for myself or others

5. I did not want to get the aggressor(s) in trouble

6. I was too embarrassed

7. I didn't think it would help

8. I was afraid someone might retaliate

9. Authorities were already on scene (or called by someone else)

10. I took care of matters myself (please specify below)

11. Other (please specify below)

These questions, whether they reported are not, were important to include because it speaks to the seriousness of the situation. If respondents did report the incident, that shows that it was so serious that they needed the assistance or help from others. However, if they did not tell, their response could also provide information about the incident (e.g. if it was serious, but happens so often that is has become normalized). This question too is important to gauge whether or not respondents are normalizing being harassed by using one of the neutralization techniques as discussed by Weiss (2013b) in her book on party subcultures and crime. Within this form of neutralization are three distinct forms of rationale, "minimizing harm, excuses and condemning complainers" (Weiss 2013b: p. 124).

Only minimizing harm and excuses will be discussed, as they are most relevant to the current study. Students who party can defend their life-style by downplaying the bad outcomes that sometimes happen as a result of harm (e.g. minimizing harms) (Weiss 2013b). However, for 
non-partiers, they use minimizing harm by making the best out of bad situations that they believe they have no control over, in allegiance to their fellow peers (Weiss 2013b). The second rationale of excuses, allows students to forgive or dismiss the wrongdoings of their peers because they were drunk (Weiss 2013b). Being wasted has become a socially acceptable form of a "get out of jail free card" for students at party schools (Weiss 2013b: p.126). Whether students minimize harm or make excuses for the behaviors of their peers will speak volumes to not only the environment that incidents of harassment occur in, but will also illuminate how such incidents are handled by the students and the University.

Bystander intervention. This section focused on bystander intervention from the perspective of the target. Even though bystander intervention is not the primary focus of the current study, it was important to include this question because of the potential affect that witnesses could have on situations of harassment. First respondents were asked, "Were there witnesses to this incident" (coded as $0=$ no, $1=$ yes). If students' selected yes, they were then asked, "If YES, did a witness intervene to help in any way (defending you verbally, or physically protecting you)" (coded as $0=$ no, $1=$ yes)? This question was followed by, "How did a witness help (check all that apply)"? The answer options provided were:

1. Yelled something at the aggressor(s) to get them to stop

2. Physically intervened to restrain or stop the aggressor(s)

3. Called authorities

4. Other (please specify)

Respondents were then asked, "Did a witness do anything that made the situation worse" (coded as $0=$ no, $1=$ yes)? If they selected yes, they then were given an open-ended question and were asked to "please describe how witnesses made the situation worse". These questions are important because as mentioned in the bullying section, witnesses possess as much power as the aggressor does, and can help a witness in more ways than the obvious, or do more harm 
(Pöyhönen, Juvonen, and Salmivalli 2012; Salmivalli, Voeten, and Poskiparta 2011;

StopBullying 2012).

Impacts and consequences of being targeted. The final section focuses on how the incident made the targets feel and the ways, if any, that the target was negatively impacted by being harassed because of their weight. First, students were asked, "How serious was the incident"? The answer options provided were:

1. Not serious at all; almost forgot about it

2. Somewhat serious; it was not please but it had no lingering impact on me

3. Very serious; it had a very negative impact on me

Secondly, respondents were asked, "Which of the following consequences, if any, have you experienced due to being harassed"? The respondents could have selected from the following:

1. Missed classes/dropped a course

2. Missed work/changed jobs

3. Avoid/stopped going to school events (sports games, etc.)

4. Avoid/stopped going to other social events (parties, etc.)

5. Avoid/stopped going to certain locations on campus

6. Avoid/stopped going to student bars/clubs

7. Avoid/stopped socializing with University peers

8. None of the above

9. Other (specify here)

This variable was recoded by collapsing responses into the variable, consequences, where missed class/work (which combined Missed classes/dropped a course and Missed work/changed jobs) was coded as 0, avoidance of locations (combined Avoid/stopped going to school events, Avoid/stopped going to certain locations on campus, and Avoid/stopped going to student bars) was coded as 1 . In addition, avoidance of peers (combined Avoid/stopped going to other social events and Avoid/stopped socializing with University peers) was coded as 2, and none of the above was coded as 3 and other was coded as 4 . The above question was included to determine whether students were experiencing hostile environments; whether respondents' daily activities and routines were altered around incidents of harassment. 
In the next to last question respondents were asked, "Which of the following best represents how the incident made you feel". They could have selected from the following:

1. It upset me

2. It angered me

3. I was afraid for my safety

4. I was embarrassed

5. I became depressed

6. It made me self-conscious

7. It had no negative effect on me

8. Other (please specify)

Fourth, and finally, respondents were asked, "I coped with being harassed by." They selected from the following:

1. Using alcohol/weapons

2. Carrying a weapon

3. Eating more/binge eating

4. Eating less/ developing risky eating behaviors (anorexia, bulimia, etc.)

5. Self-harm (cutting, burning, etc.)

6. Increased sexual activity

7. Lashing out at others/fighting

8. It had no effect on me

9. Other (please specify)

These final questions are important because previous research has already established the severity of effects that being harassed, especially based on weight, can take on an individual, but they could add more detail into how young adults are affected by harassment, specifically weight-based (Carr and Friedman 20005; Puhl and Brownell 2006; Schafer and Ferro 2011). The survey ended with demographic questions.

Demographic variables. Students were asked their age, gender, and race. Students were also asked whether they were a full time student. They also reported their class rank and sexual orientation. 
Self-reported body identity. Body identity was measured with the question, "On a scale from 1 to 5, how would you describe yourself in terms of body weight"? Students' responded using a 5point scale that ranged from:

1. Very underweight

2. Somewhat underweight

3. Average weight

4. Somewhat overweight

5. Very overweight

While these options are not congruent with the fat-positive language preferred in the Fat Studies literature (Wann 2009), these terms were used because it was believed that they would be the easiest and most recognizable terms for college students to identify with. However, studies on self-reports, especially where weight is concerned, raise the question of accuracy. A study by Gunnare et al. (2013) on the accuracy of weight-based self-reports on rural college students found that women and fat individuals, especially, underestimate their weight. The current study, however, will not be affected by underestimates because even if an individual did underestimate their body type, if they believed that they had been targeted for weight, they would have still selected weight as their primary reason for being targeted.

\section{Analytical Strategy}

The current study used the CHS (2013) to collect descriptive accounts of students' experiences with harassment, specifically weight-based harassment, on college campuses and surrounding areas. Responses from open-ended questions were used to supplement the quantitative results from the close-ended questions. These qualitative responses were coded by reoccurring themes. The themes used corresponded to variables in the survey (i.e. aggressor(s) descriptives, bystander intervention, response to the incident, etc.).The responses from close- 
ended questions were analyzed using descriptive statistics and bivariate analyses to provide frequencies and percentages to answer the main research questions. As this study is purely descriptive and exploratory, no hypotheses were postulated. 


\section{Chapter 6: Findings}

Describing overall harassment. The majority of students in the sample (48.4\%) said that they had never been verbally or physically harassment, but 37.3 percent of students said that they had been verbally harassed, while 12.9 percent had been both, physically and verbally harassed, and 1.4 percent of students said that they had been physically harassed. As for how often respondents were verbally harassed while on or near campus, 50 percent of students said that they had been verbally harassed at least 2-5 times. As for the frequency of physical harassment, most students (67.7\%) said that they had not been physically harassed. In comparison to high school, 48 percent of students reported that incidents of harassment happened more often in college than they did in high school. (See Appendix C).

Most respondents (35.3\%) said that they were unsure of the primary reason that they were targeted, but 27.6 percent said it was due to gender; 63 percent of the sample was females. Additionally, 15.9 percent said physical appearance, and 8.8 percent said sexual orientation. Additionally, 4.1 percent of students said they were targeted for their race or ethnicity while 3.5 percent said religion, 2.4 percent said weight, and 2.4 percent said that they believed the primary reason they were targeted for a disability. Most students said they were harassed by verbal comments (26\%), in a hotspot location (71.4\%), during a weekend (71.4\%), and at nighttime (70.3\%). Most students indicated that the aggressor(s) made contact while walking by (40.1\%), while they (the target) were alone (54.7\%). (See Appendix D and E).

An aggressor for overall harassment was most likely a White (69.4\%), male (81.9\%), who was solely responsible for the harassment (39.5\%). Respondents believed the aggressor was a University student (52.9\%), but most did not know their aggressor (64.3\%). Of the 35.6 percent of students who did know their aggressor, they reported that the aggressor was a University peer 
(38.4\%). Respondents indicated that neither they (76.5\%), nor the aggressor (33.9\%) was intoxicated at the time of the incident. (See Appendix E). Most respondents (61\%) did nothing to respond to the harassment or just ignored it. Explaining why those chose to do nothing, most respondents (24.8\%) said that they did not want to make matters worse for themselves or others. Most respondents (61.4\%) did not report the incident or tell anyone because they thought it was no big deal (28.4\%). For the 38.6 percent of students who did report the incident, most (10.5\%) told a friend.(See Appendix F).

The majority of students' $(70.2 \%)$ indicated that witnesses were present during the incident and 72.9 percent said that none of the witnesses intervened. Of the 27.1 percent who did say a witness intervened, the witness did so by yelling something at the aggressor to get them to stop (3.7\%). Fortunately, 88.5 percent of respondents reported that no witnesses made the situation worse. (See Appendix F). As for how being harassed affected respondents, most (53.5\%) said that the incident was somewhat serious, it was not pleasant but it had no lingering impact on them and that they did not experience any consequences because of being harassed (17.4\%). However, the majority of students' (17.9\%) reported that the incident angered and upset them, but felt no need to cope with being harassed because it had no effect on them (17.4\%). (See Appendix G).

Describing weight-based harassment. From the total sample of 511, 17 respondents (3.3\%) reported that they had been harassed because of their weight and in comparison to high school, 47.1 percent of students said that they had been harassed more often in college for their weight than when they were in high school. (See Appendix C). The majority of these respondents were women (82.4\%), White (94.1\%), 18-24 years old (82.4), some-what overweight (53\%), upperclassmen (58.8\%), and full-time students (88.2\%). (See Appendix B). 
The majority $(82.3 \%)$ indicated that they had been verbally harassed while 17.6 percent claimed that they had been both, physically and verbally harassed while students at the University. As for how many times these 17 individuals had been verbally harassed, most (76.5\%) said at least two to five times, 17.6 percent indicated at least once, and 5.9 percent of respondents indicated that they had been verbally harassed over 6 times. (See Appendix C). One female respondent (age 22) discussed the frequency to which she experienced harassment, when she stated:

I have experienced a number of instances where negative comments were made, and witnessed more. All too often derogatory remarks about weight issues are made. Every night I hear "fat bitch," and see gestures made towards women while those who do it laugh at the overweight women they "disapprove" of.

As for number of times being physically harassed, out of the 17 respondents, the majority $(82.3 \%)$ claimed that they had never been physically harassed. However, 11.8 percent of respondents indicated they had been physically harassed at least once, and 5.9 percent said they had been physically harassed at least 2- 5 times. (See Appendix C).

Describing target descriptives. In the sections that will be discussed next, only 14 respondents answered questions describing incidents of weight-based harassment. When looking specifically at weight, the majority $(78.6 \%)$ of the 14 respondents said they were targeted for being fat or overweight. (See Appendix B). For example, Respondent 45 (Female, aged 20) said:

I have been a victim of remarks about my weight. The guy yelled out of his car window at me walking and said, "Leggings are for skinny people, dumbass." This did not make me feel uncomfortable, it really hurt my feelings

Additionally, 21.4 percent of these 14 claimed that they were targeted for being thin or underweight, to which another female respondent (aged 20) said:

I was extremely underweight. I was called anorexic, bulimic, skeleton, etc. Two friends would always tell me I looked disgusting and gross because I was underweight. People would say they were going to break my arm "with one hand tied behind their back. 
Results from a cross-tabulation found that those who said that they were somewhat underweight were more likely to be targeted for being thin or underweight. Whereas students who said they were "average" weight, slightly "overweight", and very "overweight" were more likely to be targeted for being fat or "overweight" $\left(\chi^{2}=10.04, \mathrm{p}<.01\right)$.

As for how respondents were harassed, the majority (26\%) reported that they were verbally harassed. However, 9.3 percent of students said that they were laughed at or made fun of, 8.1 percent said they were harassed by threats or intimidating comments, 6.5 percent were physically attacked, and 3.6 percent of respondents claimed that they were followed or chased. (See Appendix D). Weight-based harassment is unique in comparison to overall harassment in that 85.7 percent of those targeted by weight were harassed by verbal comments compared to only 26 percent of the overall sample. Additionally, 71.4 percent of those targeted by weight were laughed at or made fun of compared to 9.3 percent in the overall sample. In recalling her experience with harassment, one respondent (Female, aged 24) said:

A friend of mine walked me home and on the way home, we were once again met with cruel remarks to my weight and appearance. This man with the cruel remarks was calling me a "'fat ass"" and told me I was ugly. And he physically laid his hands on me and my other friend.

Another respondent (Female, aged 22), who also experienced verbal and physical harassment, said:

One situation where I was involved my friends and I had just left the bar and we were standing on the sidewalk waiting for a cab when an athlete came up to us and started calling us all names such as hippo, ogre, fat-ass, etc. After he said all this, I obviously said something back like okay well no one cares what you think, you are nobody to me, and you just think you are above everyone else because you are an athlete. He did not like that too much so he got the rest of his athlete buddies and they all came up and starting pushing us, calling us names, etc. 
Describing the context of the incident. The majority (64.3\%) of respondents reported that they were harassed in one of the hot spot locations (e.g. locations that involve partying and alcohol), on a weekend (85.7\%), and were harassed at night (64.3\%). (See Appendix D).

One respondent (Female, aged 20) highlighted these findings when she described her experience with weight-based harassment. She said:

My friend had a Christmas party and these two guys and a girl were sitting on the staircase when people were trying to pass by. I politely asked them to move and I went to the bathroom. When I came out my friend told me that the girl called me fat to both of the guys. I confronted her; I do not even know her at all. She was rude and it hurt my feelings.

However, 28.6 percent of respondents said they were harassed in a University location (e.g. class, student union, gym), and 7.1 percent said in a public location (public transportation, restaurants, etc.). Most respondents (42.9\%) reported that the aggressor(s) made contact while walking by, however 35.7 percent reported the aggressor(s) made face-to-face contact with them, and 21.4 percent said that the aggressor(s) made contact by driving by in a car. Most respondents (64.3\%) were part of a group. (See Appendix D). An example of drive-by harassment can be found in the narrative below, from a female respondent (aged 21):

Last year, I was walking home from class up a big hill. A couple guys were driving in a truck up next to me and yelled "having some trouble there, ya fat bitch?" Then they sped off. I assumed they were semi-intoxicated. It made me feel very uncomfortable. I am very selfconscious about my weight. I was walking and they were driving, there was really no chance to intervene, unfortunately.

Another female respondent (aged 21), described the manner in which she was harassed as:

My boyfriend came to pick me up [from student employment in the student union] and we were walking to go through the door to get to the garage. That door is heavy so I was trying to pull it open and go through as these two guys were trying to walk in the [student union]. I said, "Jeez the door weighs 500 lbs." then went about my business. As I walked away one of the guys said, "She's just pissed she's so fat, she can't fit through." I did not hear, but my boyfriend did. I was upset because he did not say anything, but I was also upset because we are adults and still look to hurt people by commenting on weight. 
Describing the aggressor(s). Most respondents said that their aggressors were most likely males (78.6\%), White (78.6\%), and were in groups of 3-5 (42.9\%). (See Appendix E). Results of a cross-tabulation revealed no statistically significant relationship between the gender of the aggressor(s) and the gender of the target. However, 64.3 percent of the weight-based harassment was male-on-female, 14.3 percent was male-on-male, 14.3 percent was female-on-female, and 7.1 percent of females were targeted by males and females (See Appendix E). Respondents believed that all the aggressors were University students (50\%), but most (92.9\%) did not know their aggressor. Of the 7.1 percent of students' who did know their aggressor, they reported that the aggressor was a University peer (21.4\%). (See Appendix E). A female respondent (aged 21) supported the finding that most did not know their aggressors, however, in her particular experiences, she claims that weight-based harassment was from people that she knew.

Often it is people we do not know, yelling from a car, but when it was someone, we knew we worried about it more. I have been called fat, told I needed to work out and have had derogatory sexual comments made about me. Sexual comments were usually from strangers, but weight was usually people I knew.

A male respondent (aged 21), who not only spoke to the unfamiliarity between targets and aggressors, provided an interesting insight into the number of individuals involved and the involvement of alcohol.

There are constantly people saying things to others. During the day, it is mostly people screaming out cars as they drive by. At night, I would say mostly guys, but often girls scream at random people walking by. Usually when they are in groups and drinking.

Interestingly, most respondents indicated that their aggressors appeared drunk (35.7\%), but that they (the target) were not, when the incident occurred (71.4\%). (See Appendix E). A female respondent (aged 22) attests to this finding by stating: 
The most annoying part is the fact [of being harassed] they [the male aggressors] would not be saying these things if they were not drunk. It just seems so immature to me.

Describing target response and reporting. Most respondents (85.7\%) did nothing to respond to the harassment or just ignored it. Explaining why they chose to do nothing, most respondents $(25 \%)$ said that they did not want to make matters worse for themselves or others and that it happens all the time, what could they do. Most respondents $(50 \%)$ did not report the incident or tell anyone because again, it happens all the time, what can they do (50\%). (See Appendix F). For example, a male respondent (aged 20) stated:

Things like this happen every day, but it is not looked at as a big deal because it should be easy to ignore someone since they are only words.

However, another male respondent (aged 20) raised an interesting point when he stated, People tend to be able to shrug off rude remarks as long as they are not the victim. For the 50 percent of students who did report the incident, most (85.7\%) told a friend, 27.6 percent told a family member, and 14.3 percent told a police officer. (See Appendix F). Describing bystander intervention. The majority of students (76.5\%) indicated that witnesses were present during the incident, and 58.3 percent said that none of the witnesses intervened. Of the 41.7 percent who did say a witness intervened, the witness did so by yelling something at the aggressor to get them to stop $(60 \%)$ and by physically intervening to restrain or stop the aggressors; also, 20 percent of respondents said that a witness called the authorities. Additionally, 83.3 percent of respondents reported that no witnesses made the situation worse, but 16.7 percent said that a witness did make matters worse. (See Appendix F). In the openended responses, students elaborated on the fact that witnesses were generally present, but rarely 
does anyone intervene. A male respondent (aged 21) discussed the issues of bystander intervention at the University.

When there is intervening there are usually verbal arguments from distances, usually this just goes back and forth. However, rarely settled in a positive way if there is a step further it is violent.

Describing impacts and consequences of being targeted. As for how being harassed affect respondents, most respondents (50\%) said that the incident was somewhat serious, it was not pleasant but it had no lingering impact on them, and 14.3 percent said that it was very serious, and it had a very negative impact on them. However, 35.7 percent of respondents said that the incident was not serious at all, and that they had almost forgotten about it. Due to weight-based harassment, most respondents (35.7\%) avoided or stopped socializing with peers, and 14.3 percent avoided or stopped going to certain locations on campus. (See Appendix G). An example of avoiding locations can be found in the response from a female respondent (aged 20). She said:

I no longer go to the student gym because I feel uncomfortable working out because on numerous occasions I have been laughed at and mocked by groups of guys while I am trying to run.

Only, 35.7 percent said that they did not experience any consequences because of being targeted. The majority of respondents (71.4\%) said that the incident upset them and made them feel self-conscious. (See Appendix G). A female respondent (aged 21) discussed how the incident made her feel by stating:

I have had both girls and guys ask me if I am anorexic or bulimic because of how thin I was. I was actually hospitalized three years ago for a ruptured appendix where I dropped below 100 pounds. It took me months to years to get back to a healthy weight. And since they have said stuff, it made me uncomfortable about my appearance.

Another female respondent (aged 21) discussed how she was impacted by being harassed because of her weight when she said: 
I think the times I have felt the most uncomfortable was when a comment was made about weight or appearance. I think the times we feel most uncomfortable is when things are pointed out that we are already self-conscious about. I am a six two, but in high school and into my first years of college I was entirely convinced I was huge. I do not really blame people who made comments, because I accepted them.

While 42.9 percent said the incident embarrassed them, 35.7 percent were angered by the incident, 14.3 percent became depressed and afraid for their safety. Only 7.1 percent reported that the incident had no effect on them. Most of the respondents $(35.7 \%)$ said that they coped with being harassed by binge eating, but 14.3 percent said they developed anorexia or bulimia and by using alcohol or drugs, and 7.1 percent said that they coped by lashing out at others and fighting. However, 28.6 percent of respondents did report that the incident had no effect on them. (See Appendix G). 


\section{Chapter 7: Discussion}

Previous research has found that not only are adolescents affected by bullying, but that bullying continues into college and affects young adults as much as if not more than adolescents (Chapell et al. 2004; 2006; MacDonald and Roberts-Pittman 2010; 2012; Reason and Rankin 2006). The current study found that 47.1 percent of respondents said that they were harassed for their weight more often than they were in high school. This finding is very interesting because despite the five studies on college populations, which have confirmed the continuity of the behavior like the current study did, many individuals believe that bullying does not happen in college. The current study does not have enough data to say what causes the frequency of bullying to increase. One reason for the increase might be that students' body sizes have changed since high school. The second reason for the increase could be the party subculture of the University.

Weiss (2013b) found that for party schools, there are a multitude of minor crimes and other nuisance behaviors (e.g. harassment) that all can be explained by the party subculture. Most of these crimes are what she called intoxication crimes (Weiss 2013b). Weiss argued that “participation in the party subculture increases students' vulnerability to crime victimization" (Weiss 2013b: p. 73). Drinking not only makes individuals vulnerable to being targets of crimes, but drinking also increases the likelihood of individuals committing or participating in crime themselves (Weiss 2013b). However, the current study's findings differ from Weiss (2013b) in that most respondents $(71.4 \%)$ said that they were not targeted while intoxicated. Although the party school and the party subculture places all students at risk for being targeted, it seems that whether a fat student is intoxicated has no influence over making them vulnerable; their weight is enough of a factor for them to be singled out. 
Similar to Weiss, the current study found that most students (35.7\%) believed that all of their aggressors were intoxicated at the time of the incident. Weiss (2013b) suggested that all aggressors hold some form of bias for the individuals that they target and that alcohol merely gives aggressors an excuse for bad behavior, but the current study does not have enough data to suggest whether aggressors targeted individuals because they were drunk, held biases toward the target, or both. The current study also found as Weiss (2013b) did that most (64.3\%) respondents said that they were harassed for their weight in a hotspot location. Weiss (2013b) believed that most incidents of harassment (and crime) could be predicted by their involvement with alcohol and these hot spots (e.g. bars or parties). The reason why most harassing incidents occur in hotspots is that "there is a greater opportunity for crime to occur [in hotpots] due to the convergence of motivated offenders, vulnerable victims, and 'incapable' guardians, most of whom are intoxicated" (Weiss 2013b: p. 73).

The current study similar to the bullying and harassment literature found that not do adolescents age out of bullying (MacDonald and Roberts-Pittman 2010), but also alcohol and the party subculture plays a significant role in the frequency of harassment. The current study also found that harassment is a gendered experience. The current study found that 82.4 percent of targets were females and 78.6 percent of aggressors were males; which was to be expected considering that this finding is consistent with most of the bullying literature (CDC 2011; McDonald and Roberts-Pittman 2012; Reason and Rankin 2006; Underwood and Rosen 2014). Most of the literature on adolescents and young adults in the bullying and Fat Studies literature has found that females are more likely to be targeted while males are more likely to be the aggressors (CDC 2011; McDonald and Roberts-Pittman 2012; Reason and Rankin 2006; Underwood and Rosen 2014). While these results have practical implications, the results from 
the cross-tabulation found that there is not a statistically significant relationship between gender of aggressors and targets.

The current study also found that most respondents (42.9\%) said that their aggressors were in groups of 3-5, while they were also in a group (64.3\%). Finding that these exchanges of harassment occur between groups was an unexpected result. As there is nothing in the literature about multiple targets at once. The current study expected to capture incidents of harassment with one target and one main victim. The aggressors may have been in groups, but the dynamics were likely one primary aggressor with a few individuals who supported or assisted the primary aggressor as research on bystanders has found that witnesses can fulfill multiple roles (Pöyhönen, Juvonen, and Salmivalli 2012; Salmivalli, Voeten, and Poskiparta 2011). Another possible explanation for group behavior is the party subculture. Partying is a social event where students are most likely to attend in groups.

The current study also found as previous research has on bullying, harassment, and Fat Studies has that there are significant harms associated with bullying for young adults. The current study found that most respondents (35.7\%) coped with being harassed because of their weight by binge eating. This finding is consistent with previous findings that being the target of weight bias and stigma causes fat persons to either gain more weight or remain fat (Poretsky 2013; Puhl et al. 2007; 2011; Wann 2009). It is also important to report that most incidents of weight-based harassment were male-on-female (64.3\%).

The current study also found that 14.3 percent of respondents said that they developed risky eating behaviors (e.g. anorexia, bulimia, etc.). This finding is not surprising because in the world of eating disorders, victims usually follow a cycle. In an attempt to lose or maintain 
weight, individuals will restrict their daily intake of food by not eating or by purging. Starvation and purging lead individuals to binge, and then start the cycle all over again (Dalzell 2011) The point is that being targeted for weight has the most powerful affect over women not only psychologically but physically. Furthermore, 14.3 percent of respondents said that they coped by using alcohol or drugs and 7.1 percent said that they coped by lashing out at others and fighting. The current study also adapted the concept of hostile environments from the sexual harassment literature as a potential harm for college students; as research has found that for bullied adolescents, schools become hostile environments (Ark of Hope for Children 2013; CDC 2012; Shute 2008). The current study found that most students (35.7\%) avoided socializing with peers, while they also avoided certain locations on campus (14.3\%), and missed or dropped a course because of being harassed $(7.1 \%)$. These findings suggest that college campuses become so hostile as a result of weight-based harassment that targets altered their daily routines in order to avoid being harassed.

Even though most students $(50 \%)$ said that the behavior was somewhat serious, the coping mechanisms, consequences, and impacts of being harassed because of weight are very serious and very harmful for college students. Another major limitation of the bullying and harassment literature that no studies focus on weight as a factor (Chapell et al. 2004; 2006; MacDonald and Roberts-Pittman 2010; 2012; Reason and Rankin 2006). Research on adolescents have found that fat students are more likely than their non-fat peers to be targeted, but similar to the bullying and harassment literature the Fat Studies literature focuses on adolescents (Fox and Farrow 2009). The current study found that most respondents (78.6\%) believed they were targeted for being fat or overweight. This finding is consistent with Fox and Farrow (2009). The current study also found that $21.4 \%$ of students said they were harassed 
because of being thin or underweight. This is an important finding because although the Fat studies literature only focuses on fat persons, it does acknowledge that in a fat hating culture, all individuals are vulnerable to scrutiny for their size. These findings affirm that fat and thin persons are vulnerable to stigma and bias and that the actual weight of the target does not really matter. 


\section{Chapter 8: Conclusion}

It is an unfortunate truth that Western society has a general penchant for punishing differences (Royce 2009). Students from the current study showed how real this truth is by sharing their experiences with weight-based harassment while students at the University. These students reported that they had been punished for their perceived differences in various harmful ways, from ridicule to physical attacks. For these students their difference was their weight. However, not just fat students were targeted. The current study found that students of all sizes had been harassed for their weight. Aggressors' targeted students who categorized themselves as being underweight for being too thin and aggressors targeted students who identified as being “average" weight to "overweight" for being fat or "overweight." Results from a cross-tabulation between body identity and characteristic for being targeted suggest that all students were and are vulnerable to scrutiny for their size.

While the current study does not know what "being too thin," "average weight," or "overweight" looks like, students of varying body sizes were found to be frequently and maliciously harassed and as a result experienced significantly negative harms. These findings though disheartening are not surprising considering that 'being biased about the 'overweight' or 'obese' is still very socially acceptable” (Fernstrom 2013; as cited by Dahl 2013), and that weight-bias is "rarely challenged and often ignored "(Puhl et al. 2013; as cited by Neporent 2013). In many ways, weight-based harassment is similar to racial prejudice and prejudice based on sexual orientation, but differs in that it is no longer socially acceptable to target an individual for the color of the skin or for their sexual preference. Weight-based harassment like racial and sexual orientation prejudice singles out individuals for a difference that is beyond the targets' control. Although many assume that weight is a mutable factor it is not (Wann 2009). 
Regardless of the rationale or beliefs that aggressors use to harass others, targeting based on weight is the same as and as harmful as harassment based on race or sexual orientation. It is time that weight-based harassment is addressed in the same manner as other forms of prejudice and discrimination and taken just as seriously. To begin this focus, the current study conducted the first descriptive study to address weight-based harassment on college campuses. No other study provides as much detail on weight targeting as the current study has. The exploratory nature of the current study yielded results that extend the knowledge and fill the gaps in the bullying, harassment, and Fat Studies literature by illuminating the ways that fat bias manifests on college campuses.

The current study should be used as a foundation for future research to build upon. More research into the weight-based harassment of college students is important for the acknowledgement of weight-based harassment as a serious issue, one not to be ignored. It is important to address however that the party school atmosphere of the University may inflate and exacerbate incidents of weight-based harassment. Future research will need to correct for this limitation by either conducting a comparative study between party schools and non-party schools or use diverse populations. The small sample size and homogenous composition of the University was also a limitation of the current study. Future studies will need to acquire a larger sample size and select a more diverse University population. The sample size may be a limitation, but it is not a hindrance. Even though the findings may not be representative of all college populations, the current study did receive enough data to indicate that something is happening on college campuses in terms of weight-based harassment.

Perhaps the low numbers for the sample are indicative of the notion that it is okay to make fun of fat persons and that a hierarchy of factors exists; it is not socially acceptable to make 
fun of someone for their race or sexual orientation but it is okay to make fun of someone for their weight. Future studies will also need to address this concern. Regardless of the small size, it is important to remember that the current study only captured 17 cases. There could be more students out there who are affected by weight-based harassment like the respondents in this study reported. Even if only 17 persons have experienced harassment and been negatively affected by their experiences, it is important not to disassociate persons in this study from the numbers. The findings from the current study showed that students experienced weight-based harassment while students at the University. It is logical to assume that weight-based harassment is a behavior that has occurred in the past as illustrated in this sample, is occurring in the present, and will continue into the future if not recognized as a serious problem deserving of attention by researchers and University officials. Fat students are not protected by University policies, especially by the University in the current study. Young adults in higher education are not represented in the bullying, harassment, or Fat Studies literature, which is why the current study aimed to give a voice to any student who had been targeted because of their weight. It is time that their experiences are heard and recognized, especially since "People have no qualms aiming such overt cruelty at 'obese' people because there are few consequences. In effect, it's the last acceptable prejudice" (Puhl 2013; as cited by Neporent 2013).

Research conducted for the current study revealed that no University included weight specifically in their social justice statements. This exclusion sends a message to the student and faculty population that it is okay to target others based on weight. The Division for Diversity, Equity, and Inclusion for the University in the current study recently changed its social justice statement (Bolt 2013). Originally, the social justice statement, under section one of title IX, stated: 
The University prohibits discrimination or harassment on the basis of race, sex, age, disability, veteran status, religion, sexual orientation, color, national origin, or any other category protected by law in the administration of any of its educational programs, activities, or with respect to admission or employment (Goins 2013).

On February 11, 2013, the University changed its social justice statement to a blanket statement of inclusivity. The new social justice statement now states, "The University community is committed to creating and fostering a positive learning and working environment based on open communication, mutual respect and inclusion" (Bolt 2013). According to the Board of Governors, this blanket statement is much more positively worded because instead of listing all the groups that they do not exclude, which the Board argued could be used to justify discriminating other groups; they simply imply that they protect all groups (Bolt 2013).

Unless in Michigan, which passed an anti-weight-discrimination legislation, or six other State cities, fat persons are not protected by the law and did not meet the qualifications to be included in the University's previous statement (Puhl et al. 2008; as cited by Obesity Coalition for Action 2014). Even if it was not a matter of protection by law fat students were not in the minds of University officials in the previous statement, so it can be argued that they were not in the minds of officials for the new statement. Since other Universities also do not address weight in their social justice statements, fat students are not in the minds of University officials nationwide. The findings of the current study showed that not only were fat persons targeted, but also persons of all sizes were harassed because of their weight. The previous finding combined with the fact that the prevalence of weight-bias has only gotten worse and that research has shown that weight-bias transitions from thoughts into physical acts of discrimination (e.g. harassment) makes all Universities vulnerable to weight-based discrimination (Puhl et al. 2008). 
Supported by previous literature and the findings from the current study, it is the current study's recommendation that Universities begin to address the issue of weight-based harassment by first including fat students in their social justice statements and social justice programs. Even though research conducted on the anti-weight-discrimination legislation, passed by Michigan and six United States cities, found that allegations of weightism have not changed and rarely are any allegations ever made (Minnesota Department of Human Rights 2010). The Minnesota Department of Human Right (2010) claimed that the low reports of weight-based discrimination might be more to do with the fact that individuals may not know that their experiences were illegal or that the stigma surrounding weight-based harassment is enough to keep individuals from filing complaints rather than weight-based discrimination not occurring.

Whether including weight as a protected characteristic increases or decreases the frequency of weight-based harassment, Universities should at least acknowledge the problem to show their support for all students; that way Universities can take the initiative to create a safe space for all students and to draw a line that they do not tolerate ignorance. If weight is addressed by Universities, students who are targeted for their weight may begin to feel comfortable enough to report incidences of weight-based discrimination that they experienced on campus because they will know that their University is on their side. Where enforcement is concerned, the issue of weight-based discrimination and harassment should be addressed as other forms of harassment and discrimination are handled by the respective Universities.

If weight-based harassment is not addressed by Universities and students are affected by weight-based harassment the University will likely begin to suffer in terms of retention and attrition rates. By addressing weight-based harassment, Universities will not only protect their students, but will protect their own investments and interests. Although, recognition and social 
inclusion is just the first step to providing support for students, especially fat students. Once the University includes weight in their social justice policies, they should then work to provide adequate accommodations such as seating and spacing that can fit persons of any size.

The current study found that weight-based harassment does occur on college campuses and is a problem for many students so now is the time to address the elephant in the room and not ignore discrimination and harassment. This call to action should be addressed with more research on college populations and weight-based harassment, and for the recognition of and policy changes by Universities to reflect that weight-based harassment is a problem similar to other forms of prejudice and discrimination. Policy change may be slow and difficult, but the findings of the current study can be used by Universities to begin an open and honest discourse into how they can better protect and provide for their students. 


\section{$\underline{\text { References }}$}

Ark of Hope for Children. 2013. Bullying Info and Statistics. Breaking the Chains of Abuse. Retrieved (http://www.arkofhopeforchildren.org/issues/child-bullying-statisticsinfo\#.UmR7U1Csh8E).

American Psychological Association. 2013. Bullying and School Climate. American Psychological Association, 750 First St. NE, Washington, DC 20002-4242. Retrieved (https://www.apa.org/about/gr/issues/cyf/bullying-school-climate.aspx).

Barry L. Colleen, Victoria L. Brescoll, Kelly D. Brownell and Mark Schlesinger. 2009. Obesity Metaphors: How Beliefs about the Causes of Obesity Affect Support for Public Policy. The Milbank Quarterly, 87, No. 1, pp. 7-47.

Bauer KW, YW Yang, SB Austin. 2004. How can we stay healthy when you're throwing all of this in front of us? Findings from focus groups and interviews in middle schools on environmental influences on nutrition and physical activity. Health Educational Behaviors; $31: 34-46$.

Bayliss, M. 1995. It just shouldn't happen: The sexual harassment of schoolgirls by their male school peers. In P. Camilleri and K. Allen-Kelly (Eds.), Welfare and the diversity of practice in North Queensland. Proceedings of Practical Diversity Conference 9-10 Sept 1995, pp. 55-71. Townsville, Queensland: Centre for Social and Welfare Research, James Cook University.

Björkqvist, Kaj. 1994. Sex Differences in Physical, Verbal, and Indirect Aggression: A Review of Recent Research. Sex Roles, 30, Nos 3/4. Pp. 177-186. 
Boivin, Michel, Shelley Hymel, and Ernest V.E. Hodges. 2001. “Toward a Process View of Peer Rejection and Harassment." Peer Harassment in School: The Plight of the Vulnerable and Victimized, p. 265-288.

Bolt, John. 2013. WVU Faculty Senate adopts inclusivity statement. WVU Today. Retrieved http://wvutoday.wvu.edu/n/2013/02/11/wvu-faculty-senate-adopts-inclusivity-statementenacts-drill-guidelines-for-military-students).

Bond, L., J.B. Carlin, L. Thomas, K. Ruin, and G. Patton. 2001. Does bullying cause emotional problems? A prospective study of young teenagers. British Journal of Medicine: 323, 480-484.

Bordens, Kenneth S., and Irwin A. Horowitz. 2001. “Interpersonal Aggression?” Social Psychology. Psychology Press. Second Edition. Lawrence Erlbaum Associates, Inc., New Jersey.

Boulton, M.J., M., Trueman, and I., Flemington. 2002. Associations between secondary school pupils' definitions of bullying, attitudes towards bullying, and tendencies to engage in bullying: Age and sex differences. Educational Studies, 28:353-370.

Burgard, Deb, Elana Dykewoman, Esther Rothblum, and Pattie Thomas. 2009. Are We Ready to Throw Our Weight Around? Fat Studies and Political Activism. Pp. 334-340 in The Fat Studies Reader, edited by Sondra Solovay and Esther Rothblum. New York. New York University Press.

Bursik, Krisanne, and Julia Gefter. 2011. Still Stable After All These Years: Perceptions of Sexual Harassment in Academic Contexts. The Journal of Social Psychology, 151(3), 331-349.

Buss, A.H. 1961. The Psychology of Aggression. New York: Wiley. 
Card et.al. 2008. Direct and Indirect Aggression During Childhood and Adolescence: A MetaAnalytic Review of Gender Differences, Intercorrelations, and Relations to Maladjustment. Child Development, 79 (5). Pp. 1185-1229.

Cardin, Kathryn. 2013. Bullying in College: Silent yet Prevalent. USA TODAY. Retrieved (http://www.usatoday.com/story/news/nation/2013/10/18/college-bullying-silent-yetprevalent/3008677/).

Carr, Deborah, Michael A. Friedman. 2005. Is Obesity Stigmatizing? Body Weight, Perceived Discrimination, and Psychological Well-Being in the United States. Journal of Health and Social Behavior, 46, No. 3, pp. 244-259.

Center for Disease Control. 2011. National Youth Risk Behavior Surveillance Study. Atlanta, GA: Centers for Disease Control and Prevention, National Center for Inquiry Prevention and Control. Retrieved (http://www.cdc.gov/healthyyouth/yrbs/overall.htm).

Center for Disease Control. 2012. Understanding School Violence. Atlanta, GA: Centers for Disease Control and Prevention, National Center for Injury Prevention and Control. Retrieved (http://www.cdc.gov/violenceprevention/pdf/schoolviolence_factsheet-a.pdf).

Chapell, M., D. Casey, C. De la Cruz, J. Ferrell, J. Forman, and R. Lipkin. 2004. Bullying in college by students and teachers. Adolescence: 39, 53-64.

Chapell, M., S.L. Hasselman, T. Kitchin, S.N. Lomon, K.W. Maclver, and P. Sarullo.2006. Bullying in elementary school, high school, and college. Adolescence: 41, 633-648. Charmaraman, Linda, Ashleigh E. Jones, Nan, Stein, and Dorothy L. Espelage. 2013. Is it bullying or sexual harassment? Knowledge, attitudes, and professional development experiences of middle school staff. The Journal of School Health, 83 (6), 438-444. 
Cherry, Kendra. 2014. What is Self-Efficacy? Psychology. Retrieved (http://psychology.about.com/od/theoriesofpersonality/a/self_efficacy.htm).

Chen Y., Eunice, Molly Brown. 2012. Obesity Stigma in Sexual Relationships. Obesity Research, 13 (8), 1393-1397.

College Board.2013. West Virginia University. College Board. Retrieved (https://bigfuture.collegeboard.org/college-university-search/west-virginia-university).

Crandall CS. 1995. Do parents discriminate against their heavyweight daughters? Personal Psychology Bulletin; 21:724 -35.

Crosnoe Robert. July 2007. “Gender, Obesity, and Education.” Sociology of Education Vol. 80 no. 3, pgs. 241-260.

Curwen, Tracey, Jessica S. McNichol, and Glynn W. Sharpe. 2011. The Progression of Bullying from Elementary School to University. International Journal of Humanities and Social Science, 1 (13):pp. 47-52.

Dahl, Melissa. 2013.'Fat shaming' actually increases risk of becoming or staying obese, new study says. NBC News. Retrieved (http://www.nbcnews.com/health/diet-fitness/fatshaming-actually-increases-risk-becoming-or-staying-obese-new-f8C10751491).

Danielsdottir, S. et al. 2010. "Anti-fat prejudice reduction: A review of published studies." Obesity Facts, 3, 47-58.

Dalzell, Heidi. 2011. “The Binge, Purge, and Restrict Cycle.” Examiner. Retrieved (http://www.examiner.com/article/the-binge-purge-restrict-cycle).

Davison KK, Birch LL. 2004. Predictors of fat stereotypes among 9-year-old girls and their parents. Obesity Research, 12:86-94. 
DeRosier, M.E., A.H.N., Cillessen, J.D. Coje, and K.A. Dodge. 1994. Group social context and children's aggressive behavior. Child Development, 65: 1068-1079.

Do Something. 2014. 11 Facts about Bullying. Retrieved (https://www.dosomething.org/content/11-facts-about-bullying).

Eisenberg, M. E., D. Neumark-Sztainer., and C.L. Perry. 2003. Peer harassment, school connectedness, and academic achievement. Journal of School Health: 73, 311-316.

Ernsberger, Paul. 2009. "Does Social Class Explain the Connection Between Weight and Health.” Pp. 25-34 in The Fat Studies Reader, edited by Sondra Solovay and Esther Rothblum. New York. New York University Press.

Espelage, D., and S. Swearer. 2003. Research on school bullying and victimization: What have we learned and where do we go from here? School Psychology Review: 32(3), 365-383.

Espelage, D., M., Holt, and R., Henkel. 2003. Examination of peer-group contextual effects on aggression during early adolescence. Child Development, 74: 205-220.

Farrow Victoria, Claire, Mark, Terrant. 2009. Weight-based discrimination, body dissatisfaction and emotional eating: The role of perceived social consensus. Psychology and Health, 24 (9), 1021-1034.

Federal Communication Commission. 2009. Understanding Workplace Harassment. Federal Communication. $44512^{\text {th }}$ Street SW, Washington, DC 20554. Retrieved (http://www.fcc.gov/encyclopedia/understanding-workplace-harassment-fcc-staff).

Fekkes, M., F. Pijpers, and S. Verloove- Vanhorick. 2005. Bullying: Who does what, when and where? Involvement of children, teachers, and parents in bullying behavior. Health Education Research, 20, pp. 81-91. 
Finkelhor, David. 2013. Trends in Bullying and Peer Victimization. Crimes Against Children. Retrieved (http://www.unh.edu/ccrc/pdf/CV280_Bullying\%20and\%20Peer\%20Victimization\%20 Bulletin_1-23-13_with\%20toby\%20edits.pdf).

Flegel, K. 2006. Excess Deaths Associated with Obesity: Cause and Effect. International Journal of Obesity, 30, 1171-1172.

Forbes. 2013. West Virginia University. Forbes. Retrieved (http://www.forbes.com/colleges/west-virginia-university/).

Fox, C. L and C.V. Farrow. 2009. Global and physical self-esteem and body dissatisfaction as mediators of the relati onship between weight status and being a victim of bullying. Journal of Adolescence, 32 , 1287-1301.

Fraser, Laura. 2009 “The Inner Corset: A Brief History of Fat in the United States” Pp. 11-14 in The Fat Studies Reader, edited by Sondra Solovay and Esther Rothblum. New York. New York University Press.

Frey, K.S., M.K., Hirschstein, L.V., Edstrom, and J.L., Snell 2009. Observed reductions in school bullying, nonbullying aggression, and destructive bystander behavior: A longitudinal evaluation. Journal of Educational Psychology, 101: 466-481.

Gladstone, G. L., G.B. Parker, and G.S. Malhi. 2006. Do bullied children become anxious and depressed adults? A cross-sectional investigation of the correlates of bullying and anxious depression. The Journal of Nervous and Mental Disease: 194, 201-208. 
Goins, James. 2013. "Guidelines and Procedures Regarding Complaints of Discrimination, Harassment, and Sexual Misconduct.” Retrieved (http://diversity.wvu.edu/policies/title_ix_compliance).

Goodeman, Carol, Kimberly A. Zammitt, and Morgen Hagedorn. 2012. The Wolf in Sheep's Clothing: Student Harassment Veiled as Bullying. National Association of Social Workers.

Gunnare, Nicole A., Kathryn Silliman, and Michelle Neyman Morris. 2013. Accuracy of selfreported weight and role of gender, body mass index, weight satisfaction, weighing behavior, and physical activity among rural college students. Body Image, 10(3): pp. 406-410.

Hainer, V., A. Stunkard, M. Kunesova, J. Parizkova, V. Stich, and D.B. Allison. 2001. A Twin Study of Weight Loss and Metabolic Efficiency. International Journal of Obesity Related Metabolic Disorders, 25(4), 533-537.

Hamburger ME, K.C. Basile, A.M. Vivolo. 2011. Measuring Bullying Victimization, Perpetration, and Bystander Experiences: A Compendium of Assessment Tools. Atlanta, GA: Centers for Disease Control and Prevention, National Center for Injury Prevention and Control.

Harvard School of Public Health. 2014. Obesity Definition. The President and Fellows of Harvard College. Retrieved (http://www.hsph.harvard.edu/obesity-preventionsource/obesity-definition/).

Haskins M., Katherine, H. Edward Ransford. 1999. The Relationship between Weight and Career Payoffs Among Women. Sociological Forum, 14 (2), pp. 295-318. 
Hawker, D. S. J., and M.J. Boulton. 2000. Twenty years' research on peer victimization and psychosocial maladjustment: A meta-analytic review of cross-sectional studies. Journal of Child Psychology and Psychiatry and Allied Disciplines: 41, 441-455.

Hawkins, D.L., D.J., People, and W.M., Craig 2001. Naturalistic observations of peer interventions in bullying. Social Development, 10: 512.

Hunte, Haslyn, E.R. 2011. Association Between Perceived Interpersonal Everyday Discrimination and Waist Circumference Over a 9-Year Period in the Midlife Development in the United States Cohort Study. American Journal of Epidemiology, 173 (11), pg. 1232-1239.

Juvonen, Jaana, and Sandra Graham. 2001. Self-Views versus Peer Perceptions of Victim Status among Early Adolescents. Pp. 105-124 in Peer Harassment in School: The Plight of the Vulnerable and Victimized.

Kolata, G. 2006. The New Age: So Big and Healthy Grandpa Wouldn’t Even Know You. New York Times. Retrieved (http://www.nytimes.com/2006/07/30/health/30age.html).

Kochenderfer, Becky, and Gary W. Ladd. 2001. Variations in Peer Victimization: Relations to Children's Maladjustment. Peer Harassment in School: The Plight of the Vulnerable and Victimized, p. 25-48.

Latner JD, AJ Stunkard. 2003.Getting worse: the stigmatization of obese children. Obesity Research.; 11:452-6.

Lyons, Pat. 2009. Prescription for Harm: Diet Industry Influence, Public Health Policy, and the 'Obesity Epidemic. Pp. 75-87 in The Fat Studies Reader, edited by Sondra Solovay and Esther Rothblum. New York. New York University Press. 
MacDonald, Christine D., and Bridget Roberts-Pittman. 2010. Cyberbullying among college students: prevalence and demographic differences. Procedia Social and Behavioral Sciences: 9 (2010) 2003-2009.

MacDonald, Christine D., and Bridget Roberts-Pittman. 2012. Who Bullies College Students? Prevalence Rates and Aggressor Types. Not published.

Matthews, Laura. 2011. Ashlynn Connor, 10, Allegedly Commits Suicide Because of Bullying. International Business Times. Retrieved (http://www.ibtimes.com/ashlynn-conner-10allegedly-commits-suicide-because-bullying-369832).

McHugh, Maureen C. and Ashley E. Kasardo 2012. Anti-fat Prejudice: The Role of Psychology in Explication, Education and Eradication. Sex Roles, 66:617-627.

Minnesota Department of Human Rights. 2010. Weight-bias Laws: Tipping the Scales against Prejudice? Weight Bias. Received (http://mn.gov/mdhr/education/articles/rs10_2weightlaws.html).

NAAFA. 2013. Why I should support NAAFA. About us. Retrieved (http://www.naafaonline.com/dev2/about/index.html).

Nansel, Tonja R., Mary Overpeck, Ramani S. Pilla, W. June Ruan, Bruce Simons-Morton, and Peter Scheidt. 2001. Bullying Behaviors Among US Youth: Prevalence and Association with Psychosocial Adjustment. Journal of the American Medical Association, 285 (16) 1094-2100.

National Crime Prevention Council. 2010. Bullying. Arlington, Virginia. Retrieved (http://www.ncpc.org/topics/bullying).

National Education Association. 1994. Report on Discrimination Due to Physical Size. Retrieved (http://lectlaw.com/files/con28.htm). 
Neporent, Liz. 2013. Stigma Against Fat People, the Last Acceptable Prejudice, Studies Find. $A B C$ News. Retrieved (http://abcnews.go.com/Health/stigma-obese-acceptableprejudice/story $? \mathrm{id}=18276788 \&$ singlePage $=$ true $)$.

Neumark-Sztainer D, Falkner N, Story M, Perry C, Hannan PJ, Mulert S. 2002. Weight-teasing among adolescents: correlations with weight status and disordered eating behaviors. International Journal of Obesity Related Metabolic Disorders; 26:123-31.

Neumark-Sztainer D, Story M, Harris T.1999. Beliefs and attitudes about obesity among teachers and school health care providers working with adolescents. Journal of Nutritional Education; 31:3-9.

NIH. 2014. Adipose Tissue. Genetics Home Reference. U.S. National Library of Medicine. Retrieved (http://ghr.nlm.nih.gov/glossary=adiposetissue).

Obesity Action Coalition. 2014. "Weight Discrimination: A Socially Acceptable Injustice.” By Rebecca Puhl. Retrieved (http://www.obesityaction.org/educational-resources/resourcearticles-2/weight-bias/weight-discrimination-a-socially-acceptable-injustice).

O’Connell, P., D., Pepler, and W., Craig. 1999. Peer involvement in bullying: Insights and challenges for intervention. Journal of Adolescence, 22: 437-452.

Olweus, D. 1978. Aggression in Schools. Bullies and Whipping Boys. New York: Wiley. Olweus, D. 1994. Bullying at school: Long-term outcomes for the victims and an effective school-based intervention program. In: L. R. Huesmann (Ed.), Aggressive behavior: Current perspectives (pp. 97-130). New York: Plenum Press.

Parker-Pope, Tara. 2008. "Fat Bias Worse for Women." The New York Times. Retrieved (http://well.blogs.nytimes.com/2008/03/31/fat-bias-worse-for- 
women/?_php=true\&_type=blogs\&_r=0\&module=ArrowsNav\&contentCollection=Heal th\&action=keypress\&region=FixedLeft\&pgtype $=$ Blogs $)$.

Poretsky, Golda. 2013. Your Fat is (Allegedly) Killing you!!!: Weight Stigma and The Dangerous Nocebo Effect. Body Love Wellness. Retrieved (http://www.bodylovewellness.com/2013/09/23/your-fat-is-allegedly-killing-youweight-stigma-and-the-dangerous-nocebo-effect/).

Price JH, Desmond SM, Krol RA, Snyder FF, O'Connell JK. 1987. Family practice physicians' beliefs, attitudes, and practices regarding obesity. American Journal of Preventative Medicine; 3:339-45.

Pöyhönen, Virpir, Jaana Juvonen, and Christina Salmivalli. 2012. Standing Up for the Victim, Siding with the Bully or Standing by? Bystander Responses in Bullying Situations. Outcome Expectations and Values 21(4): pp. 722- 738.

Puhl, R. M. and Brownell, K. D. 2001. Bias, discrimination and obesity. Obesity research: 9:788-805.

Puhl, RM, CA Moss-Racusin, and MD Schwartz. 2007. Internalization of weight-bias: Implications for binge eating and emotional well-being. Obesity, 15(1):19-23.

Puhl, R.M., Andreyeva, T., \& Brownell, K.D (2008). Perceptions of weight discrimination: prevalence and comparison to race and gender discrimination in America. International Journal of Obesity. doi: 10.1038/ijo.2008.22

Andreyeva, T., Puhl, R.M., \& Brownell, K.D (2008). Changes in Perceived Weight Discrimination Among Americans, 1995-1996 through 2004-2006. Obesity. oi:10.1038/oby.2008.35 
Puhl, R.M., J. Luedicke, and C. Heuer. 2011. Weight-based Victimization toward overweight adolescents: observations and reactions of peers. Journal of School Health, 81(11):696703.

Reason, Robert D., and Susan R. Rankin. 2006. College Students' Experiences and Perceptions of Harassment on Campus: An Exploration of Gender Differences. College Student Affairs Journal, Vol. 26, Issue 1: 7-29.

Rigby, K., and B., Johnson. 2006. Expressed readiness of Australian schoolchildren to act as bystanders in support of children who are being bullied. Educational Psychology, 26: pp. $425-440$.

Rigby, K., and P.T. Slee. 1991. Bullying among Australian school children: Reported behavior and attitudes toward victims. Journal of Social Psychology, 131, 615-627

Roehling MV. 1999. Weight-based discrimination in employment: psychological and legal aspects. Personal Psychology, 52:969-1017.

Royce, Tracy. 2009. The Shape of Abuse: Fat Oppression as a Form of Violence Against Women. Pp. 151-157 in The Fat Studies Reader, edited by Sondra Solovay and Esther Rothblum. New York. New York University Press.

Salmivalli, Christina, K. Lagerspetz, K., Bjorkqvist, K., Osterman, and A. Kaukiainen. 1996. Bullying as a group process: Participant roles and their relations to social status within the group. Aggressive Behavior, 22, 1-15.

Salmivalli, Christina, and M. Voeten. 2004. Connections between attitudes, group norms, and behavior in bullying situations. International Journal of Behavioral Development, 28: 246-258. 
Salmivalli, Christina, Marinus Voeten, and Elisa Poskiparta. 2011. Bystanders Matter:

Associations Between Reinforcing, Defending, and the Frequency of Bullying Behavior in Classrooms. Journal of Clinical Child and Adolescent Psychology, 40: pp. 668-676.

Schafer H., Markus, Ferraro F., Kenneth. 2011. The Stigma of Obesity: Does

Perceived Weight Discrimination Affect Identity and Physical Health? Social Psychology Quarterly, 74 (1): p76-97, 22p, 5 Charts.

Schwartz MB, O’Neal H, Brownell KD, Blair S, Billington C. 2003. Weight bias among health professionals specializing in obesity. Obesity Research, 11:1033-9.

Schwartz MB, Vartanian L, Nosek B, Brownell KD. 2006. The influence of one's own body weight on implicit and explicit anti-fat bias. Obesity Research, 14:440 -7.

Sherer, Nickerson. 2010. Anti-bullying practices in American schools: Perspectives of school psychologists. Psychology in the Schools, 47 (3): pp. 217-229.

Shute, Rosalyn, Larry Owens, Phillip Slee. 2008. Everyday Victimization of Adolescent Girls by Boys: Sexual Harassment, Bullying, or Aggression? Sex Roles, 58:477-489.

Solovay, Sondra, and Esther Rothblum. 2009. Introduction. Pp. 1-7 in The Fat Studies Reader, edited by Sondra Solovay and Esther Rothblum. New York. New York University Press.

Strauss Esmay Associates, LLP. 2011. Harassment, Intimidation, and Bullying Prevention Training: Characteristic of Bullies and Targets (Script excerpts). Retrieved (http://www.burltwpsch.org/uploads/17/files/Characteristics\%20of\%20Bullies(1).pdf).

Stop Bullying. 2012. Stop Bullying Campaign. U.S. Department of Health and Human Services. Retrieved (http://www.stopbullying.gov/index.html). 
Sutin, Angelina R., and Antonio Terracciano. 2013. Perceived Weight Discrimination and Obesity. PLOSONE. Retrieved (http://www.plosone.org/article/info\%3Adoi\%2F10.1371\%2Fjournal.pone.0070048).

Twemlow, S. W., P. Fonagy, and F.C. Sacco. 2004. The role of the bystander in the social architecture of bullying and violence in schools and communities. Annals of the New York Academy of Sciences, 1036, 215-232.

Underwood, Marion K., and Lisa H. Rosen. 2014. Gender and Bullying: Moving Beyond Mean Differences to Consider Conceptions of Bullying, Processes by which Bullying Unfolds, and Cyber Bullying. To appear in D. Espelage and S. Swearer (Eds.), Bullying in North American Schools, $2^{\text {nd }}$ Edition. To be published by Routledge. Retrieved (http://icbtt.arizona.edu/sites/default/files/Underwood_and_Rosen_(in_press).pdf).

U.S. Department of Education. 2011. Bullying Isn't Just 'Kids being Kids. Homeroom. Retrieved (https://www.ed.gov/blog/2011/03/bullying-summi/).

Wang SS, KD Brownell, TA Wadden.2004. The influence of the stigma of obesity on overweight individuals. International Journal of Obesity, 28:1333-7.

Wang Youfa, and Mary Beydoun.2007. The Obesity Epidemic in the United States-Gender, Age, Socioeconomic, Racial/Ethnic, and Geographic Characteristics: A Systematic Review and Meta-Regression Analysis. Epidemiologic Review, 29.

Wann, Marilynn. 2009. Fat Studies: An Invitation to Revolution. The Fat Studies Reader. edited by Sondra Solovay and Esther Rothblum. New York. New York University Press.

Watts, K. and Cranney, J. The nature and implications of implicit weight bias. Current Psychiatry Reviews, 5, 110-126. 
Weinstock, Jacqueline, and Michelle Krehbiel. 2009. Fat Youth as Common Targets for Bullying. Fat Studies reader: p. 120:126. edited by Sondra Solovay and Esther Rothblum. New York. New York University Press.

Weiss, Karen (a). 2013. College Harassment Survey. West Virginia University. Department of Sociology and Anthropology. Morgantown, WV.

Weiss, Karen (b). 2013. Party School: Crime, Campus, and Community. Boston: Northeastern University Press.

Whitney, Irene, Dabie Nabuzoka, and Peter K. Smith. 1992. Bullying in schools: Mainstream and special needs. Support for Learning, 7(1): pp. 3-7. 


\section{$\underline{\text { Appendices }}$}

Appendix A. Overall Sample Descriptives ( $N=511)$

\begin{tabular}{|c|c|c|}
\hline & Base $N$ & Sample \% \\
\hline \multicolumn{3}{|l|}{ Age } \\
\hline $18-24$ & 469 & 93.8 \\
\hline 25 and over & 31 & 6.2 \\
\hline \multicolumn{3}{|l|}{ Gender } \\
\hline Male & 185 & 37.0 \\
\hline Female & 315 & 63.0 \\
\hline \multicolumn{3}{|l|}{ Race } \\
\hline White & 443 & 85.7 \\
\hline Black & 17 & 3.3 \\
\hline Hispanic/Latino & 17 & 3.3 \\
\hline Other & 40 & 7.7 \\
\hline \multicolumn{3}{|l|}{ Class rank } \\
\hline Underclassmen & 248 & 49.5 \\
\hline Upperclassmen & 253 & 50.5 \\
\hline \multicolumn{3}{|l|}{ Full Time Student } \\
\hline Yes & 488 & 97.4 \\
\hline No & 13 & 2.6 \\
\hline \multicolumn{3}{|l|}{ Sexual Orientation } \\
\hline Heterosexual & 447 & 89.2 \\
\hline Bisexual & 23 & 4.6 \\
\hline Gay/Lesbian & 21 & 4.2 \\
\hline Transgender & 3 & 0.6 \\
\hline Other & 7 & 1.4 \\
\hline \multicolumn{3}{|l|}{ Body Identity } \\
\hline Very Underweight & 4 & 0.8 \\
\hline Somewhat Underweight & 56 & 11.2 \\
\hline Average Weight & 312 & 62.4 \\
\hline Somewhat Overweight & 114 & 22.8 \\
\hline Very Overweight & 14 & 2.8 \\
\hline
\end{tabular}


Appendix B. Weight-Based ${ }^{\mathrm{a}}$ Sample Descriptives

\begin{tabular}{|c|c|c|}
\hline & Base $N$ & Sample \% \\
\hline \multicolumn{3}{|l|}{ Age } \\
\hline $18-24$ & 15 & 88.2 \\
\hline 25 and over & 2 & 11.8 \\
\hline \multicolumn{3}{|l|}{ Gender } \\
\hline Male & 3 & 17.6 \\
\hline Female & 14 & 82.4 \\
\hline \multicolumn{3}{|l|}{ Race } \\
\hline White & 16 & 94.1 \\
\hline Black & 1 & 5.9 \\
\hline \multicolumn{3}{|l|}{ Class rank } \\
\hline Underclassmen & 7 & 41.1 \\
\hline Upperclassmen & 10 & 58.9 \\
\hline \multicolumn{3}{|l|}{ Full Time Student } \\
\hline Yes & 15 & 88.2 \\
\hline No & 2 & 11.8 \\
\hline \multicolumn{3}{|l|}{ Body Identity } \\
\hline Somewhat Underweight & 3 & 17.6 \\
\hline Average Weight & 3 & 17.6 \\
\hline Somewhat Overweight & 9 & 53.0 \\
\hline Very Overweight & 2 & 11.8 \\
\hline \multicolumn{3}{|c|}{$\begin{array}{l}\text { What characteristic of weight do you suspect } \\
\text { that you were targeted? }\end{array}$} \\
\hline Being fat or overweight & 11 & 78.6 \\
\hline Being thin or underweight & 3 & 21.4 \\
\hline
\end{tabular}

${ }^{a}$ The sub-set of the overall sample for weight-targets is $n=17$, but in last question there is a base $N$ of 14. 
Appendix C. Comparison between Overall Harassment ${ }^{\mathrm{a}}$ and Weight-Based Harassment ${ }^{\mathrm{b}}$

\begin{tabular}{|c|c|c|c|c|}
\hline & \multicolumn{2}{|c|}{ Overall } & \multicolumn{2}{|c|}{ Weight-Based } \\
\hline & Base $N$ & Sample \% & Base $N$ & Sample \% \\
\hline \multicolumn{5}{|l|}{$\begin{array}{l}\text { While at the University, have you ever been } \\
\text { verbally or physically harassed? }\end{array}$} \\
\hline Yes, verbal harassment & 185 & 37.3 & 14 & 82.3 \\
\hline Yes, both verbal and physical harassment & 64 & 12.9 & 3 & 17.6 \\
\hline Yes, physical harassment & 7 & 1.4 & 0 & 0.0 \\
\hline No & 240 & 48.4 & 0 & 0.0 \\
\hline \multicolumn{5}{|l|}{$\begin{array}{l}\text { How many times have you been verbally } \\
\text { harassed? }\end{array}$} \\
\hline None & 12 & 4.7 & 0 & 0.0 \\
\hline 1 & 39 & 15.4 & 3 & 17.6 \\
\hline $2-5$ & 127 & 50.0 & 13 & 76.5 \\
\hline 6 or more & 76 & 29.9 & 1 & 5.9 \\
\hline \multicolumn{5}{|l|}{$\begin{array}{l}\text { How many times have you been physically } \\
\text { harassed? }\end{array}$} \\
\hline None & 172 & 67.7 & 14 & 82.3 \\
\hline 1 & 39 & 15.4 & 2 & 11.8 \\
\hline $2-5$ & 35 & 13.8 & 1 & 5.9 \\
\hline 6 or more & 8 & 3.2 & 0 & 0.0 \\
\hline \multicolumn{5}{|c|}{$\begin{array}{l}\text { In comparison to high school, such incidents } \\
\text { happen? }\end{array}$} \\
\hline More often & 121 & 48.0 & 8 & 47.1 \\
\hline Less often & 83 & 32.9 & 6 & 35.3 \\
\hline About the same & 48 & 19.0 & 3 & 17.6 \\
\hline
\end{tabular}

${ }^{\mathrm{a}}$ The overall sample had a sample size of 511, but base $N$ varied by question.

${ }^{\mathrm{b}}$ The sub-set of the overall sample for weight-targets is $n=17$. 
Appendix D. Comparison for the Context of the Situation.

\begin{tabular}{|c|c|c|c|c|}
\hline & \multicolumn{2}{|c|}{ Overall $^{\mathrm{a}}$} & \multicolumn{2}{|c|}{ Weight-Based $^{b}$} \\
\hline & Base $N$ & Sample \% & Base $N$ & Sample \% \\
\hline \multicolumn{5}{|l|}{$\begin{array}{l}\text { How were you harassed? (Check all that } \\
\text { apply) }\end{array}$} \\
\hline Verbal Comments & 132 & 26.0 & 12 & 85.7 \\
\hline Laughed at or made fun of & 47 & 9.3 & 10 & 71.4 \\
\hline Threats or intimidating comments & 41 & 8.1 & 3 & 21.4 \\
\hline Restricted/was told not to go to certain places & 12 & 2.4 & 2 & 14.3 \\
\hline Physically attacked & 33 & 6.5 & 1 & 7.1 \\
\hline Had items thrown at you & 13 & 2.6 & 1 & 7.1 \\
\hline Followed or chased & 18 & 3.6 & 0 & 0.0 \\
\hline Sent threatening emails/text messages & 10 & 2.0 & 0 & 0.0 \\
\hline Had embarrassing photos posted online & 5 & 1.0 & 0 & 0.0 \\
\hline Other & 13 & 2.1 & 0 & 0.0 \\
\hline \multicolumn{5}{|l|}{ Where specifically did this incident occur? } \\
\hline Hot Spot locations & 86 & 50.0 & 9 & 64.3 \\
\hline University locations & 26 & 15.1 & 4 & 28.6 \\
\hline Public locations & 3 & 1.8 & 1 & 7.1 \\
\hline Other locations & 57 & 33.1 & 0 & 0.0 \\
\hline \multicolumn{5}{|l|}{$\begin{array}{l}\text { Which day of the week did the incident } \\
\text { occur? }\end{array}$} \\
\hline Weekday & 46 & 28.6 & 2 & 14.3 \\
\hline Weekend & 115 & 71.4 & 12 & 85.7 \\
\hline \multicolumn{5}{|l|}{ What time did the incident occur? } \\
\hline Day & 49 & 29.6 & 5 & 35.7 \\
\hline Night & 116 & 70.3 & 9 & 64.3 \\
\hline \multicolumn{5}{|l|}{ What manner did the incident occur? } \\
\hline While walking by & 69 & 40.1 & 6 & 42.9 \\
\hline Face-to-face & 66 & 38.4 & 5 & 35.7 \\
\hline While driving by in a car & 18 & 10.5 & 3 & 21.4 \\
\hline Electronically & 12 & 7.0 & 0 & 0.0 \\
\hline Other & 7 & 4.1 & 0 & 0.0 \\
\hline \multicolumn{5}{|l|}{ Were you alone or part of a group? } \\
\hline Alone & 94 & 54.7 & 5 & 35.7 \\
\hline Part of a group & 78 & 45.3 & 9 & 64.3 \\
\hline
\end{tabular}

${ }^{a}$ The overall sample had a sample size of 511, but base $N$ varied by question.

${ }^{\mathrm{b}}$ The sub-set of the overall sample for weight-targets is $n=17$. 
Appendix E. Comparison for Descriptives of the Aggressor(s).

\begin{tabular}{|c|c|c|c|c|}
\hline & \multicolumn{2}{|c|}{ Overall $^{\mathrm{a}}$} & \multicolumn{2}{|c|}{ Weight-Based $^{b}$} \\
\hline & Base $N$ & Sample \% & Base $N$ & Sample \% \\
\hline \multicolumn{5}{|c|}{ Number responsible for the harassment? } \\
\hline 1 & 68 & 39.5 & 5 & 35.7 \\
\hline 2 & 48 & 27.9 & 3 & 21.4 \\
\hline $3-5$ & 42 & 24.4 & 6 & 42.9 \\
\hline More than 6 & 14 & 8.1 & 0 & 0.0 \\
\hline \multicolumn{5}{|c|}{ What was the gender of the aggressor(s)? } \\
\hline Male & 140 & 81.9 & 11 & 78.6 \\
\hline Female & 18 & 10.5 & 2 & 14.3 \\
\hline Both male and female & 13 & 7.6 & 1 & 7.1 \\
\hline \multicolumn{5}{|c|}{ Gender composition of incident. } \\
\hline Male - on- Female & 32 & 54.2 & 9 & 64.3 \\
\hline Male - on- Male & 20 & 34.0 & 2 & 14.3 \\
\hline Female - on - Female & 4 & 6.8 & 2 & 14.3 \\
\hline Mixed gender - on - Female & 2 & 3.0 & 1 & 7.1 \\
\hline Mixed gender - on - Male & 1 & 2.0 & 0 & 0.0 \\
\hline \multicolumn{5}{|c|}{ What was the race of the aggressor(s)? } \\
\hline White & 118 & 69.4 & 11 & 78.6 \\
\hline Mixed races & 23 & 13.5 & 1 & 7.1 \\
\hline Black & 15 & 8.8 & 0 & 0.0 \\
\hline Unsure & 14 & 8.2 & 2 & 14.3 \\
\hline \multicolumn{5}{|c|}{$\begin{array}{l}\text { Was/were the aggressor(s) University } \\
\text { students? }\end{array}$} \\
\hline Yes, all & 91 & 52.9 & 7 & 50.0 \\
\hline Yes, some & 7 & 4.1 & 3 & 21.4 \\
\hline Unsure & 67 & 39.0 & 4 & 28.6 \\
\hline No & 7 & 4.1 & 0 & 0.0 \\
\hline \multicolumn{5}{|c|}{ Did you know the aggressor(s)? } \\
\hline Yes, all & 50 & 29.2 & 1 & 7.1 \\
\hline Yes, some & 11 & 6.4 & 0 & 0.0 \\
\hline No & 110 & 64.3 & 13 & 92.9 \\
\hline \multicolumn{5}{|c|}{$\begin{array}{l}\text { Did the aggressor(s) appear to be } \\
\text { intoxicated? }\end{array}$} \\
\hline Yes, all & 49 & 28.7 & 5 & 35.7 \\
\hline Yes, some & 31 & 18.1 & 2 & 14.3 \\
\hline No & 58 & 33.9 & 3 & 21.4 \\
\hline Unsure & 33 & 19.3 & 4 & 28.6 \\
\hline
\end{tabular}

${ }^{\mathrm{a}}$ The overall sample had a sample size of 511 , but base $N$ varied by question.

${ }^{b}$ The weight-based sample had a base $N$ of 17, but only 14 answered these questions. 
Appendix F. Comparison for Target Response and Bystander Intervention.

\begin{tabular}{|c|c|c|c|c|}
\hline & \multicolumn{2}{|c|}{ Overall $^{\mathrm{a}}$} & \multicolumn{2}{|c|}{ Weight-Based $^{b}$} \\
\hline & Base $N$ & Sample \% & Base $N$ & Sample \% \\
\hline \multicolumn{5}{|l|}{ How did you respond? } \\
\hline I did nothing/ignored it & 105 & 61.0 & 12 & 85.7 \\
\hline Both verbally and physically fought back & 9 & 5.2 & 1 & 7.1 \\
\hline Yelled, said something back & 26 & 15.1 & 0 & 0.0 \\
\hline Physically pushed, shoved back & 5 & 2.9 & 0 & 0.0 \\
\hline Other & 27 & 15.7 & 1 & 7.1 \\
\hline \multicolumn{5}{|l|}{ If you chose to do nothing, why? } \\
\hline It happens all the time, what can you do? & 12 & 9.6 & 3 & 25.0 \\
\hline I did not want to make matters worse for myself or others & 31 & 24.8 & 3 & 25.0 \\
\hline I did not want to bring any more attention to myself & 25 & 20.0 & 2 & 16.7 \\
\hline It was no big deal & 13 & 10.4 & 1 & 8.3 \\
\hline I didn't think it would help & 15 & 12.0 & 1 & 8.3 \\
\hline $\begin{array}{l}\text { The aggressor(s) were drunk and probably didn't know } \\
\text { what they were doing }\end{array}$ & 9 & 7.2 & 0 & 0.0 \\
\hline I was too embarrassed & 2 & 1.6 & 0 & 0.0 \\
\hline I did not want to get the aggressor(s) in trouble & 1 & 0.8 & 0 & 0.0 \\
\hline Other & 17 & 13.6 & 2 & 16.7 \\
\hline \multicolumn{5}{|l|}{ Did you report the incident or tell anyone? } \\
\hline Yes & 66 & 38.6 & 7 & 50.0 \\
\hline No & 105 & 61.4 & 7 & 50.0 \\
\hline \multicolumn{5}{|l|}{ Were there witnesses to this incident? } \\
\hline Yes & 120 & 70.2 & 13 & 76.5 \\
\hline No & 51 & 29.8 & 4 & 23.5 \\
\hline \multicolumn{5}{|l|}{ If YES, did a witness intervene to help in any way)? } \\
\hline Yes & 36 & 27.1 & 5 & 41.7 \\
\hline No & 97 & 72.9 & 7 & 58.3 \\
\hline \multicolumn{5}{|l|}{ How did a witness help? (Check all that apply) } \\
\hline Yelled something at the aggressor(s) to get them to stop & 19 & 3.7 & 3 & 60.0 \\
\hline Physically intervened to restrain or stop the aggressor(s) & 13 & 2.6 & 3 & 60.0 \\
\hline Called authorities & 4 & 0.8 & 1 & 20.0 \\
\hline Other & 17 & 3.4 & 0 & 0.0 \\
\hline \multicolumn{5}{|l|}{$\begin{array}{l}\text { Did a witness do anything that made the situation } \\
\text { worse? }\end{array}$} \\
\hline Yes & 16 & 11.5 & 2 & 16.7 \\
\hline No & 123 & 88.5 & 10 & 83.3 \\
\hline
\end{tabular}


Appendix G. Comparisons for Impacts and Consequences of Harassment.

\begin{tabular}{|c|c|c|c|c|}
\hline & \multicolumn{2}{|c|}{ Overall $^{\mathrm{a}}$} & \multicolumn{2}{|c|}{ Weight-Based $^{\mathrm{b}}$} \\
\hline & Base $N$ & Sample \% & Base $N$ & Sample \% \\
\hline \multicolumn{5}{|l|}{ How serious was the incident? } \\
\hline Not serious at all; almost forgot about it & 53 & 30.8 & 5 & 35.7 \\
\hline $\begin{array}{l}\text { Somewhat serious; it was not pleasant but it had } \\
\text { no lingering impact on me }\end{array}$ & 92 & 53.5 & 7 & 50.0 \\
\hline $\begin{array}{l}\text { Very serious; it had a very negative impact on } \\
\text { me }\end{array}$ & 97 & 15.7 & 2 & 14.3 \\
\hline \multicolumn{5}{|l|}{$\begin{array}{l}\text { Which of the following consequences, if any, } \\
\text { have you experienced due to being harassed } \\
\text { (Check all that apply)? }\end{array}$} \\
\hline Avoid socializing with peers & 59 & 11.6 & 5 & 35.7 \\
\hline Avoid locations on campus & 70 & 13.7 & 2 & 14.3 \\
\hline Missed class/work & 24 & 4.8 & 1 & 7.1 \\
\hline Other & 14 & 2.8 & 1 & 7.1 \\
\hline None of the above consequences & 88 & 17.4 & 5 & 35.7 \\
\hline \multicolumn{5}{|l|}{$\begin{array}{l}\text { How did the incident make you feel (Check } \\
\text { all that apply)? }\end{array}$} \\
\hline It made me self-conscious & 61 & 12.0 & 10 & 71.4 \\
\hline It upset me & 91 & 17.9 & 10 & 71.4 \\
\hline It made me embarrassed & 56 & 11.0 & 6 & 42.9 \\
\hline It angered me & 91 & 17.9 & 5 & 35.7 \\
\hline I was afraid for my safety & 56 & 11.0 & 2 & 14.3 \\
\hline I became depressed & 26 & 5.1 & 2 & 14.3 \\
\hline It had no negative effect on me & 25 & 4.9 & 1 & 7.1 \\
\hline Other & 3 & 0.6 & 0 & 0.0 \\
\hline \multicolumn{5}{|l|}{$\begin{array}{l}\text { How did you cope with being harassed } \\
\text { (Check all that apply)? }\end{array}$} \\
\hline Eating more/binge eating & 9 & 1.8 & 5 & 35.7 \\
\hline $\begin{array}{l}\text { Eating less/developing risky eating behaviors } \\
\text { (anorexia, bulimia, etc.) }\end{array}$ & 13 & 2.6 & 2 & 14.3 \\
\hline Using alcohol or drugs & 16 & 3.2 & 2 & 14.3 \\
\hline Lashing out at others/fighting & 8 & 1.6 & 1 & 7.1 \\
\hline Carrying a weapon & 9 & 1.8 & 0 & 0.0 \\
\hline Increased sexual activity & 7 & 1.4 & 0 & 0.0 \\
\hline Self-harm (cutting, burning, etc.) & 6 & 1.2 & 0 & 0.0 \\
\hline It had no effect on me & 88 & 17.4 & 4 & 28.6 \\
\hline Other & 36 & 7.1 & 2 & 14.3 \\
\hline
\end{tabular}

${ }^{a}$ The overall sample had a sample size of 511, but base $N$ varied by question.

${ }^{b}$ The weight-based sample had a base $N$ of 17, but only 14 answered these questions. 